\title{
Genetically predicted bipolar disorder is causally associated with an increased risk of breast cancer: a two-sample Mendelian randomization analysis
}

\author{
Haoxin Peng ${ }^{1,2 \#} \wedge$, Xiangrong Wu ${ }^{1,2 \#}$, Fan Ge ${ }^{1,3 \#}$, Zhenyu Huo ${ }^{1,2 \#}$, Yaokai Wen ${ }^{1,2}$, Caichen $\mathrm{Li}^{1}$, \\ Jinsheng Lin ${ }^{1,2}$, Hengrui Liang ${ }^{1}$, Ran Zhong ${ }^{1}$, Jun Liu ${ }^{1}$, Runchen Wang ${ }^{1,2}$, Jianxing He ${ }^{1}$, Wenhua Liang ${ }^{1}$ \\ ${ }^{1}$ Department of Thoracic Oncology and Surgery, China State Key Laboratory of Respiratory Disease \& National Clinical Research Center for \\ Respiratory Disease, the First Affiliated Hospital of Guangzhou Medical University, Guangzhou, China; ${ }^{2}$ Nanshan School, Guangzhou Medical \\ University, Guangzhou, China; ${ }^{3}$ First Clinical School, Guangzhou Medical University, Guangzhou, China \\ Contributions: (I) Conception and design: H Peng, X Wu, Y Wen, C Li; (II) Administrative support: H Peng, X Wu, Y Wen, C Li; (III) Provision \\ of study materials or patients: J Lin, H Liang, R Zhong, Y Wen; (IV) Collection and assembly of data: H Peng, X Wu; (V) Data analysis and \\ interpretation: H Peng, X Wu; (VI) Manuscript writing: All authors; (VII) Final approval of manuscript: All authors. \\ "These authors contributed equally to this work. \\ Correspondence to: Jianxing He, MD, PhD, FACS, FRCS. AATS active member, ESTS member, Department of Thoracic Surgery, the First Affiliated \\ Hospital of Guangzhou Medical University; China State Key Laboratory of Respiratory Disease \& National Clinical Research Center for Respiratory \\ Disease, Guangzhou, China. Email: drjianxing.he@gmail.com; Wenhua Liang, MD. Department of Thoracic Oncology, the First Affiliated Hospital \\ of Guangzhou Medical University, China State Key Laboratory of Respiratory Disease \& National Clinical Research Center for Respiratory Disease, \\ Guangzhou, China. Email: liangwh1987@163.com.
}

Background: Epidemiologic findings suggested that bipolar disorder (BD) may be associated with an increased risk of breast cancer. However, there are few studies that comprehensively evaluating their correlation and the causal effect remains unknown. With a two-sample Mendelian randomization (MR) approach, we were able to investigate the causal relationship between genetically predicted BD and breast cancer risk.

Methods: Utilizing 14 BD-related single nucleotide polymorphisms (SNPs) as instrumental variables (IVs) identified by the latest genome-wide association studies (GWASs), we investigated the correlation between genetically predicted BD and breast cancer risk using summary statistics from the Breast Cancer Association Consortium, with a total of 122,977 cases and 105,974 controls. Study-specific estimates were summarized using inverse variance weighted (IVW) method. To further evaluate the pleiotropy, the weighted median and the MR-Egger regression method were implemented. Subgroup analyses according to different immunohistochemical types of breast cancer were also conducted.

Results: MR analyses demonstrated that genetically predicted BD was causally associated with an increased risk of breast cancer $(\mathrm{OR}=1.059 ; 95 \% \mathrm{CI}: 1.008-1.112, \mathrm{P}=0.0229)$. When results were examined by immunohistochemical type, no causal effects between genetically predicted BD and estrogen receptor (ER)positive breast cancer $(\mathrm{OR}=1.049,95 \% \mathrm{CI}: 0.999-1.102 \mathrm{P}=0.0556)$ and ER-negative breast cancer (OR $=1.032$, 95\% CI: $0.953-1.116 \mathrm{P}=0.4407)$ were observed. Additionally, the results demonstrated the absence of the horizontal pleiotropy.

Conclusions: Our findings provided evidence for a causal relationship between genetically predicted BD and an increased risk of breast cancer overall. Further studies are warranted to investigate the underlying mechanism.

Keywords: Bipolar disorder (BD); breast cancer; Mendelian randomization (MR)

Submitted Jul 17, 2020. Accepted for publication Nov 30, 2020.

doi: $10.21037 /$ atm-20-5372

View this article at: http://dx.doi.org/10.21037/atm-20-5372

\footnotetext{
^ ORCID 000-0002-3423-3748.
} 


\section{Introduction}

Breast cancer is the major cause of cancer death and the most common malignancy in women (1). In 2020, the American Cancer Society estimates that approximately 279,100 new breast cancer cases and 42,690 cancer deaths will occur in the United States (2). Mortality from breast cancer in North America and the European Union (EU) has decreased in the past few years, mainly due to early detection and effective systemic therapies (3). However, breast cancer is still considered to be the leading cause of death from cancers in less developed regions and second to lung cancer in more developed countries, possibly because of the lack of early diagnosis and effective treatment (4). Consequently, early identification of potentially modifiable risk factors is of significance for better prevention of breast cancer.

Individuals with serious mental illness (SMI)_defined as a mental illness like schizophrenia or bipolar disorder (BD) which leads to substantial functional impairment, are especially likely to experience significantly reduced life expectancy (5). Much of this difference is correlated with preventable and treatable chronic diseases, like cancer, which ranked as the second leading cause of death of SMI patients (6). Epidemiologic evidence to date regarding mental illness and cancer is growing. In specific, studies investigating the breast cancer incidence among individuals with $\mathrm{BD}$ are relatively inconsistent. Due to the nature of conventional observational studies, previous findings are susceptible to reverse causality or potential confounders. For instance, few studies had investigated lifestyle factors in relation to breast cancer risk among people with BD, which possibly contributing to the biased results caused by confounding factors that increase both risk of BD and breast cancer. Consequently, findings are insufficient to draw a definitive conclusion on the causal relationship between BD and breast cancer risk from present studies.

Mendelian randomization (MR) is a novel approach to investigate the causality between an exposure and an outcome using germline genetic variants as instrumental variables (IVs) (7). On the basis of Mendel's second law that genetic variations are randomly distributed at conception, they are generally independent of environmental risk factors, and temporally precede both risk factors and the disease process (8). Consequently, MR offers a means to investigate the causal relationship between an exposure and an outcome in a non-experimental way (9). MR approach is capable to prevent the potential limitations that are common in conventional observational studies, such as reverse causality, confounding, and measurement error when the fundamental principles of MR are not violated (10). In regard to $\mathrm{BD}$, genetic variants have been confirmed to play a crucial role in $\mathrm{BD}$ since the heritability of $\mathrm{BD}$ was estimated approximately $10.7 \%$ (11). Simultaneously, with the published genetic data from the Breast Cancer Association Consortium (BCAC) (122,977 cases and 105,974 controls), the two-sample MR analysis offers a means to evaluate the causality between $\mathrm{BD}$ and breast cancer, overall and among specific immunohistochemical type, greatly increasing the scope and statistical power of MR (12). Furthermore, we conducted additional MR analyses to investigate whether genetically predicted BD would be associated with common confounders and mediators of breast cancer risk, like smoking status, use of antipsychotics and so on, based on existing literature (13-16).

Using a two-sample MR method, our study could provide the latest evidence for evaluating a causal relationship between $\mathrm{BD}$ and risk of breast cancer.

\section{Methods}

\section{Identification of single nucleotide polymorphisms (SNPs) associated with BD}

We conducted a literature search to identify and extracted information for SNPs that were associated with BD at the genome-wide significance level $\left(\mathrm{P}<5 \times 10^{-8}\right)$. We identified

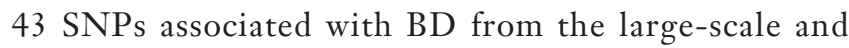
most recent genome-wide association studies (GWASs) publication, including 30 SNPs from Stahl et al. (51,710 European ancestry cases and 169,188 European ancestry controls) (17), 6 SNPs from Hou et al. (2,137 European ancestry cases and 3,168 European ancestry controls) (18), 6 SNPs from Ikeda et al. (2,964 Japanese ancestry and 61,887 Japanese ancestry control) (11) and 1 SNPs from Baum et al. (772 European ancestry cases and 876 European ancestry controls) (Table S1) (19). These 43 SNPs explained approximately $10.7 \%$ of the variation in BD across individuals. The F-statistic of our study was $27,434.10$, which was much larger than the conventional value of 10 , indicating the instruments used strongly predicted $\mathrm{BD}$ (20). In addition, the number required for $80 \%$ power in breast cancer with an odds ratio (OR) of 1.37 was at least 11,908 subjects (21) (Table 1). Consequently, it was adequate to conduct a strong genetic instrument based on these 43 SNPs. Of these 43 SNPs, 19 SNPs 
Table 1 Power for conventional Mendelian randomization analysis (two-sided $\alpha=0.05$ )

\begin{tabular}{|c|c|c|c|c|c|c|}
\hline $\begin{array}{l}\text { Exposure/genetic } \\
\text { instrument }\end{array}$ & $\begin{array}{l}\text { R-squared (of variance } \\
\text { in } B D \text { phenotype) }\end{array}$ & $\begin{array}{l}\text { Actual n } \\
\text { (BCAC) }\end{array}$ & $\begin{array}{l}\text { Proportion of } \\
\text { cases (BCAC) }\end{array}$ & $\begin{array}{l}\text { Observational } \\
\text { OR }\end{array}$ & $\begin{array}{c}\mathrm{n} \text { required } \\
\text { for } 80 \% \text { power }\end{array}$ & $\begin{array}{l}\text { Power at } \\
\text { actual } n\end{array}$ \\
\hline BD/14 SNPs & $10.7 \%$ & 228,951 & 0.537 & 1.37 & 11,908 & 1.00 \\
\hline
\end{tabular}

BD, bipolar disorder; BCAC, the Breast Cancer Association Consortium; SNP, single nucleotide polymorphism; OR, odds ratio.

Table 2 Characteristics of SNPs selected as instrumental variables for Mendelian randomization analysis

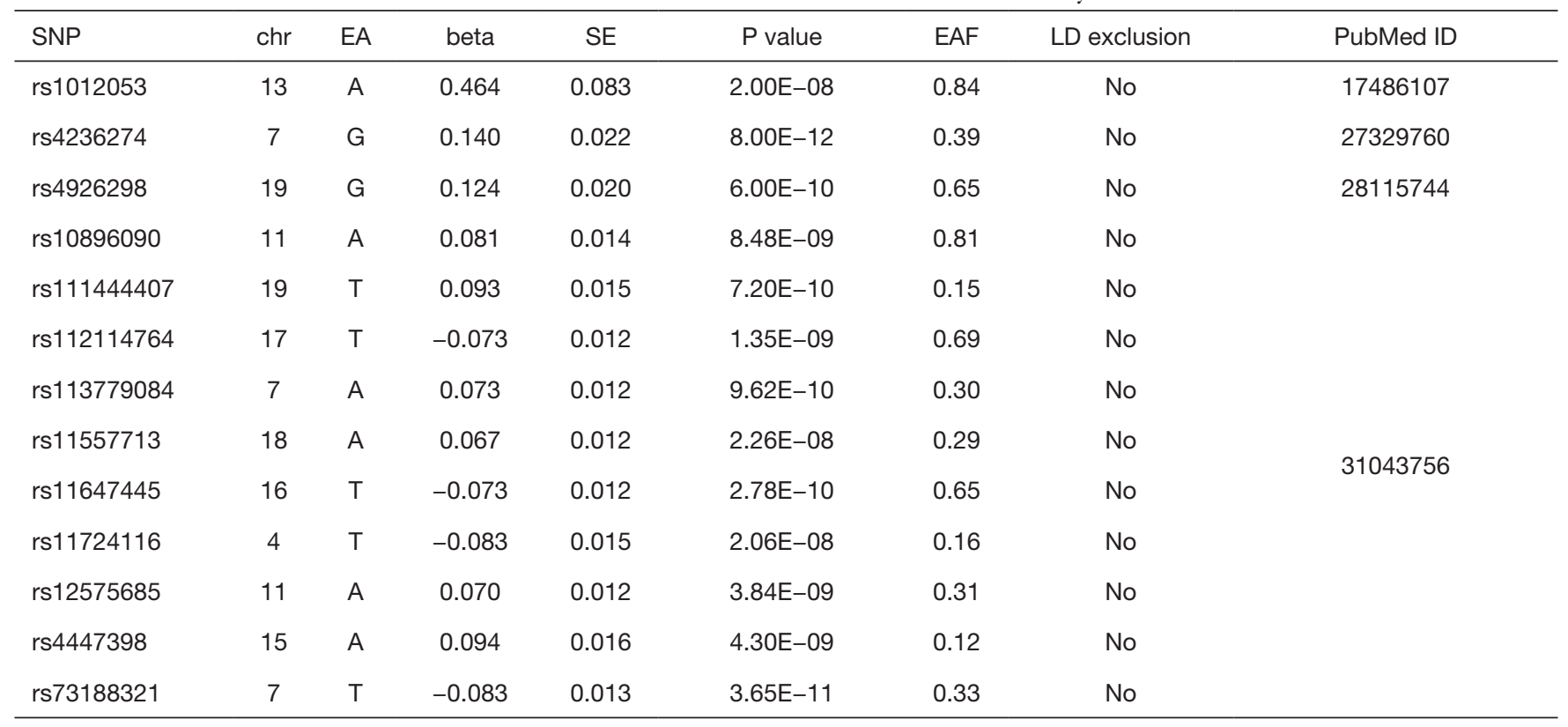

SNP, single-nucleotide polymorphism; chr, chromosome; SE, standard errors; EAF, effect allele frequency; LD, linkage disequilibrium.

were excluded using linkage disequilibrium (LD) analysis once mutual LD conjugately surpassed the limited value $\left(\mathrm{R}^{2}<0.001\right)$ (Table S1), rs12576775, rs1487441, rs174576, rs2388334, rs28456, rs3804640, rs4332037 and rs9834970 were removed for being palindromic with intermediate allele frequencies, rs7122539 and rs17183814 were removed due to the association with other phenotypes $(22,23)$. Eventually, 14 SNPs were brought into the final IVs set (Table 2).

\section{Study participants of breast cancer}

Formed in April 2005, the Breast Cancer Association Consortium (BCAC) is a forum of investigators of casecontrol studies that is conducted with the aim of identifying genes related to the risk of breast cancer. Derived from the European ancestry, genetic data of 122,977 breast cancer cases and 105,974 controls from BCAC (Table 3) were used as epidemiological individual-level data. According to the existence of estrogen receptor (ER) and responsiveness to estrogen of tumor cells growth, subgroup analyses including ER-positive breast cancer $(69,501$ cases and 105,974 controls) and ER-negative (21,468 cases and 105,974 controls) breast cancer were implemented. We retrieved summary data (the effects of each of the SNPs on the breast cancer; effect sizes and standard errors) from BCAC (http:// bcac.ccge.medschl.cam.ac.uk/).

\section{Statistical analysis}

To investigate MR estimates of BD for breast cancer, we utilized several MR approaches. First, a random effects inverse variance weighted (IVW) Wald-type estimator was conducted to derive a MR estimate of multiple IVs. Given that the SNP had a cumulative effect on BD, the IVW estimate of the causal effect could be combined with the ratio estimate and standard error of a single SNP using the method of Burgess et al. (24). All previous hypotheses were 
Table 3 Details of studies included in Mendelian randomization analyses

\begin{tabular}{|c|c|c|c|c|c|c|}
\hline Trait & First author & Consortium & Number of cases & Number of controls & Sample size & Year \\
\hline ER+ breast cancer & Michailidou K & BCAC & 69,501 & 105,974 & 175,475 & 2017 \\
\hline ER- breast cancer & Michailidou K & $\mathrm{BCAC}$ & 21,468 & 105,974 & 127,442 & 2017 \\
\hline
\end{tabular}

ER, estrogen receptor; BCAC, the Breast Cancer Association Consortium.

assumed to be consistent with the previously described genetic variant $\mathrm{P}(\mathrm{P}=1 \ldots \mathrm{P})$; which was associated with the mean change in $\mathrm{BD}\left(X_{p}\right)$ of the risk factor observed with each other variant allele with standard error $\left(\sigma_{X p}\right)$ and observed $\left(Y_{p}\right)$ logarithmic change in the outcome of each allele with standard error $\left(\sigma_{Y_{p}}\right)$. The calculation was as follows:

$$
\hat{\beta}_{I V W}=\frac{\sum_{i=1}^{P} X_{p} Y_{p} \sigma_{Y p}^{-2}}{\sum_{i=1}^{p} X_{p}^{2} \sigma_{Y p}^{-2}} ; \operatorname{se}\left(\hat{\beta}_{I V W}\right)=\sqrt{\frac{1}{\sum_{i=1}^{p} X_{p}^{2} \sigma_{Y p}^{-2}}}
$$

Corresponding OR and $95 \%$ confidence intervals (CI) were calculated using $\hat{\beta}_{I V W}$ and $\operatorname{se}\left(\hat{\beta}_{I V W}\right)$.

Three basic assumptions were made in our MR analysis: (I) the SNPs were robustly associated with BD; (II) the SNPs were independent of breast cancer, that was, the SNPs had no pleiotropic effect through pathways other than $\mathrm{BD}$; and (III) the SNPs were independent of factors that confounded the BD-breast cancer relation (25). The first assumption was met since the chosen SNPs were selected at the genome-wide significance threshold of $\mathrm{P}<5 \times 10^{-8}$ and the F-statistics was 27,434.1 ( F>100). MR-Egger and weighted median method were performed to test for the second assumption indirectly. For sensitivity analysis, we obtained global pleiotropic effects from the MR-Egger analyses based on the intercept. Leave-one-out analyses were carried out to evaluate whether the estimation of MR was determined or biased by a SNP separately by successively omitting a single SNP. It is worth noting that cancer patients, especially women and young adults, are likely to experience persisting negative mood, like depression and cancer-related fears, which may potentially lead to mental health illness (26). Therefore, to further explore the causal relationship, we performed a bi-directional MR (27) to seek whether breast cancer status would reversely cause BD.

Aiming at verifying the third assumption, we employed additional MR analyses to investigate whether genetic predisposition towards $\mathrm{BD}$ could be associated with the potential confounders and mediators underlying the mechanisms from BD to breast cancer. Previous studies have reported that people with BD tend to live an unhealthy lifestyle compared with the general population, like more alcohol consumption and cigarette exposure. Simultaneously, epidemiological studies suggested that alcohol consumption and cigarette exposure are correlated with an increased risk of breast cancer $(13,15)$. Consequently, the unhealthy lifestyles could possibly act as the mediators from BD to breast cancer. In addition, obesity is associated with risk of breast cancer and may increase risk of $\mathrm{BD}$. Hence, obesity is considered to be a potential confounder of the BD-breast cancer relationship (28). Lithium, a major antipsychotics used for the treatment of $\mathrm{BD}$, has been recognized as a potent inhibitor of glycogen synthase kinase-3 $\beta$ (GSK-3 $\beta$ ) which plays an important role in the survival, growth, and differentiation of breast cancer cells (29). Hence, use of lithium product could be a potential confounding factor of breast cancer among BD patients. Eventually, conventional MR was applied to investigate whether genetically predicted $\mathrm{BD}$ was associated with confounding factors and mediators mentioned above. Genetic summary data on obesity were extracted from Genetic Investigation of ANthropometric Traits (GIANT) (http://giant.princeton. edu/) and data on alcohol assumption were obtained from the UK Biobank (https://www.ukbiobank.ac.uk/). Genetic instruments for use of lithium product were gained from the MRC Integrative Epidemiology Unit (MRC-IEU) (http://www.bristol.ac.uk/integrative-epidemiology/) (Table 4). MR analyses were performed in $\mathrm{R}$ (version 4.0.0) using the package TwoSampleMR (version 0.5.4) (30).

\section{Power calculation}

Based on the approach described by Burgess (31), our sample size of 122,977 breast cancer cases and 105,974 controls had an estimated $100.0 \%$ power to investigate the previously estimated causal effect size of $\mathrm{BD}(\mathrm{OR}=1.37)$ at a significance level of 0.05 , assuming the SNPs explain a total of $10.7 \%$ variance of BD based on previous studies (11). 
Table 4 Details of studies included in confounders and mediators of bipolar disorder

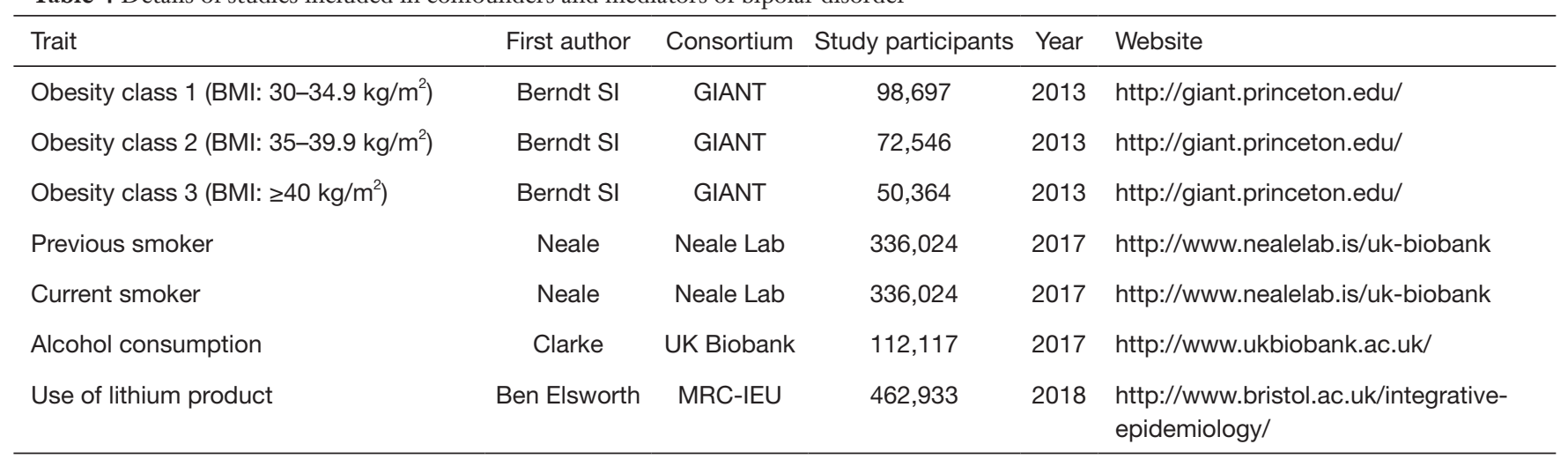

BMI, body mass index; GIANT, Genetic Investigation of ANthropometric Traits; MRC-IEU, MRC Integrative Epidemiology Unit.

\section{Results}

\section{Causal effect between BD and breast cancer}

Using conventional IVW method, genetically predicted BD was causally associated with a $5.9 \%$ higher risk of breast cancer (OR $=1.059$; $95 \%$ CI: $1.008-1.112, \mathrm{P}=0.0229)$ (Figure 1). As expected, the association was consistent in sensitivity analyses using weighted median $(\mathrm{OR}=1.043$, 95\% CI: $1.003-1.086, \mathrm{P}=0.0356)$ and MR-Egger method $(\mathrm{OR}=1.055,95 \%$ CI: 0.973-1.143, $\mathrm{P}=0.2187)$. Similar causal trends in ER-positive breast cancer $(\mathrm{OR}=1.049$, 95\% CI: $0.999-1.102, \mathrm{P}=0.0556)$ and $\mathrm{ER}$-negative breast cancer $(\mathrm{OR}=1.032,95 \% \mathrm{CI}$ : $0.953-1.116, \mathrm{P}=0.4407)$ were discovered whereas they were lack of statistical significance (Table 5). Meanwhile, as for the causal effect of single SNP analysis, rs1012053, rs111444407 and rs4236274 were observed to causally correlate with an increased risk of breast cancer among BD patients (Figure 2, Table S2). Using breast cancer as an exposure phenotype and $\mathrm{BD}$ as an outcome, our bi-directional MR result demonstrated an absence of causal relationship between breast cancer and $\mathrm{BD}(\mathrm{OR}=1.001,95 \% \mathrm{CI}: 0.913-1.098, \mathrm{P}=0.9799)$ (Table S3).

\section{Sensitivity analysis}

Leave-one-out sensitivity analyses demonstrated that no single SNP was strongly driving the overall effect of BD on breast cancer (Figures S1-S3). No evidence for the existence of directional pleiotropy in the MR-Egger regression analysis was presented (Table 6, Table S4). We found that the $\mathrm{P}$ values for the intercept were non statistically significant and the estimates adjusted for pleiotropy demonstrated null effects (intercept $\beta=0.0006, P=0.9133$ for breast cancer; intercept $\beta=0.0022, \mathrm{P}=0.9140$ for $\mathrm{ER}$-positive breast cancer; intercept $\beta=-0.0060, \mathrm{P}=0.5217$ for ERnegative breast cancer). Heterogeneity was not observed (Table 6, Table S5). To identify whether the association between genetically predicted $\mathrm{BD}$ and breast cancer was influenced by potential confounders and mediators, additional MR analyses in conventional IVW method were applied, demonstrating that genetically predicted BD was not causally associated with obesity (OR $=0.982,95 \% \mathrm{CI}$ : $0.900-1.071, \mathrm{P}=0.6756$ for obesity class $1 ; \mathrm{OR}=1.004,95 \%$ CI: $0.888-1.136, \mathrm{P}=0.9446$ for obesity class 2 ; $\mathrm{OR}=0.931$, 95\% CI: $0.756-1.146, \mathrm{P}=0.4979$ for obesity class 3), alcohol consumption $(\mathrm{OR}=0.999,95 \% \mathrm{CI}$ : $0.987-1.012, \mathrm{P}=0.9170)$, smoking $(\mathrm{OR}=0.998,95 \% \mathrm{CI}$ : 0.991-1.005, $\mathrm{P}=0.5092$ for previous smoker; OR $=1.000,95 \%$ CI: 0.995-1.005, $\mathrm{P}=0.8926$ for current smoker) and use of lithium product $(\mathrm{OR}=1.005,95 \% \mathrm{CI}: 0.977-1.034, \mathrm{P}=0.710)$ (Table 7, Table S6). Consequently, all three assumptions of MR foundations were consistent in our study when combining the sensitivity analyses above, revealing relatively great credibility of the outcome.

\section{Discussion}

This two-sample MR analysis provided evidence for causality between genetically predicted BD and an increased risk of breast cancer overall. When results were examined by immunohistochemical type, no causal associations were observed for ER-positive breast cancer nor ER-negative breast cancer risks. Furthermore, to identify the potential confounders and mediators between BD and breast cancer, we observed that genetic predisposition towards $\mathrm{BD}$ was 


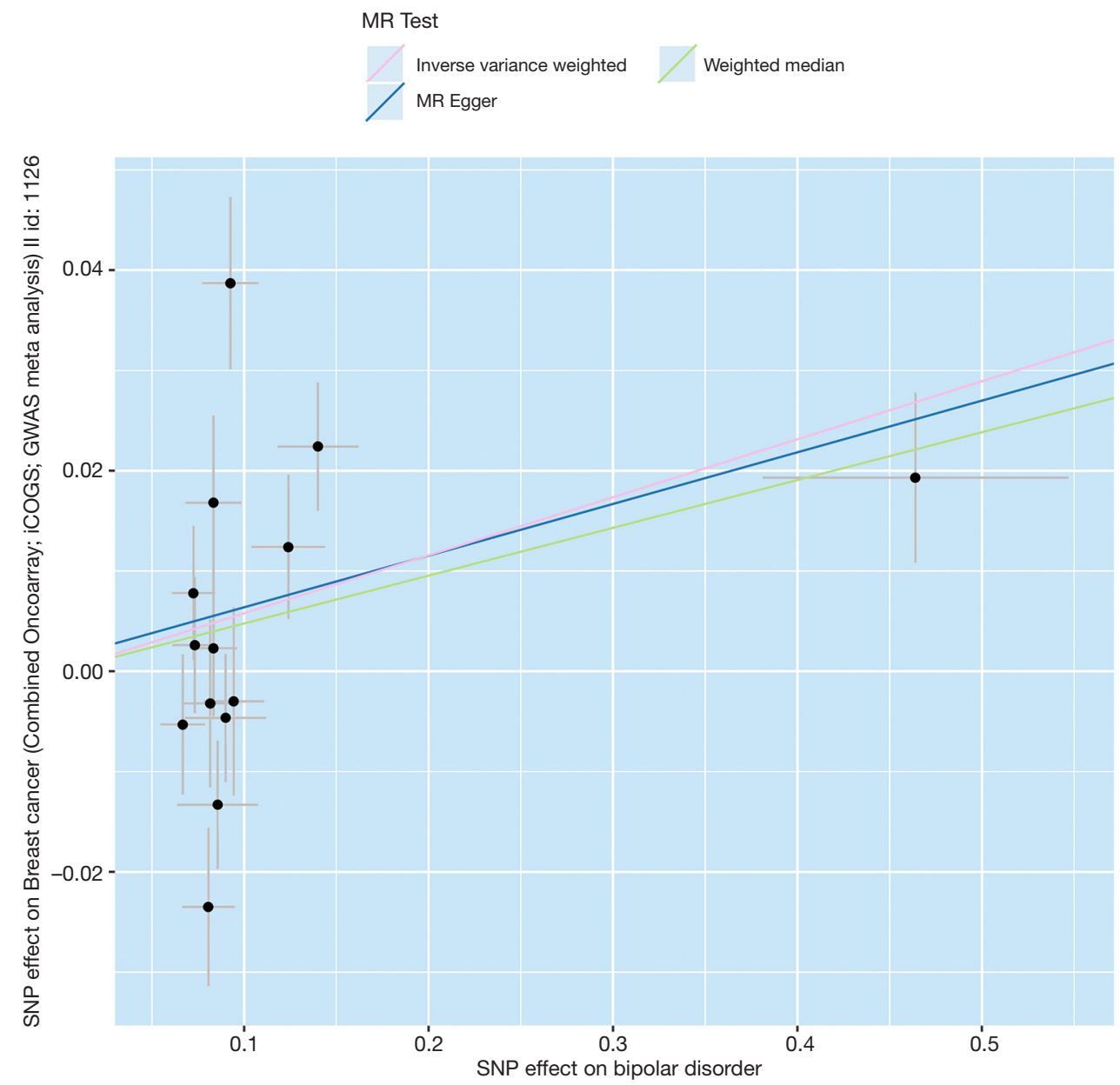

Figure 1 Scatter plot of SNPs associated with bipolar disorder and their risk of breast cancer. A plot relating the SNP effect on bipolar disorder (x-axis, SD units) and SNP effect on breast cancer [y-axis, $\log (\mathrm{OR})]$ with $95 \%$ confidence intervals. The Mendelian randomization (MR) regression slopes of the lines correspond to the causal estimates using each of the three different methods [inverse variance weighted (IVW), MR-Egger, and weighted median]. The pink line shows causal regression estimates from IVW. The blue line shows causal regression estimates from MR-Egger. The green line shows causal regression estimates from weighted median. SNP, single nucleotide polymorphism; OR, odds ratio.

Table 5 Mendelian randomization estimates of the associations between bipolar disorder and risk of breast cancer overall and immunohistochemical types

\begin{tabular}{|c|c|c|c|c|c|c|}
\hline Outcome & \multicolumn{2}{|c|}{ IVW method } & \multicolumn{2}{|l|}{ MR-Egger } & \multicolumn{2}{|c|}{ Weighted median method } \\
\hline Breast cancer overall & $1.059(1.008,1.112)$ & 0.0229 & $1.055(0.973,1.143)$ & 0.2187 & $1.043(1.003,1.086)$ & 0.0356 \\
\hline ER-positive breast cancer & $1.049(0.999,1.102)$ & 0.0556 & $1.037(0.957,1.124)$ & 0.3968 & $1.036(0.990,1.084)$ & 0.1277 \\
\hline ER-negative breast cancer & $1.032(0.953,1.116)$ & 0.4407 & $1.066(0.938,1.213)$ & 0.3427 & $1.052(0.985,1.124)$ & 0.1318 \\
\hline
\end{tabular}

OR, odds ratio; ER, estrogen receptor; IVW, inverse variance weighted. 


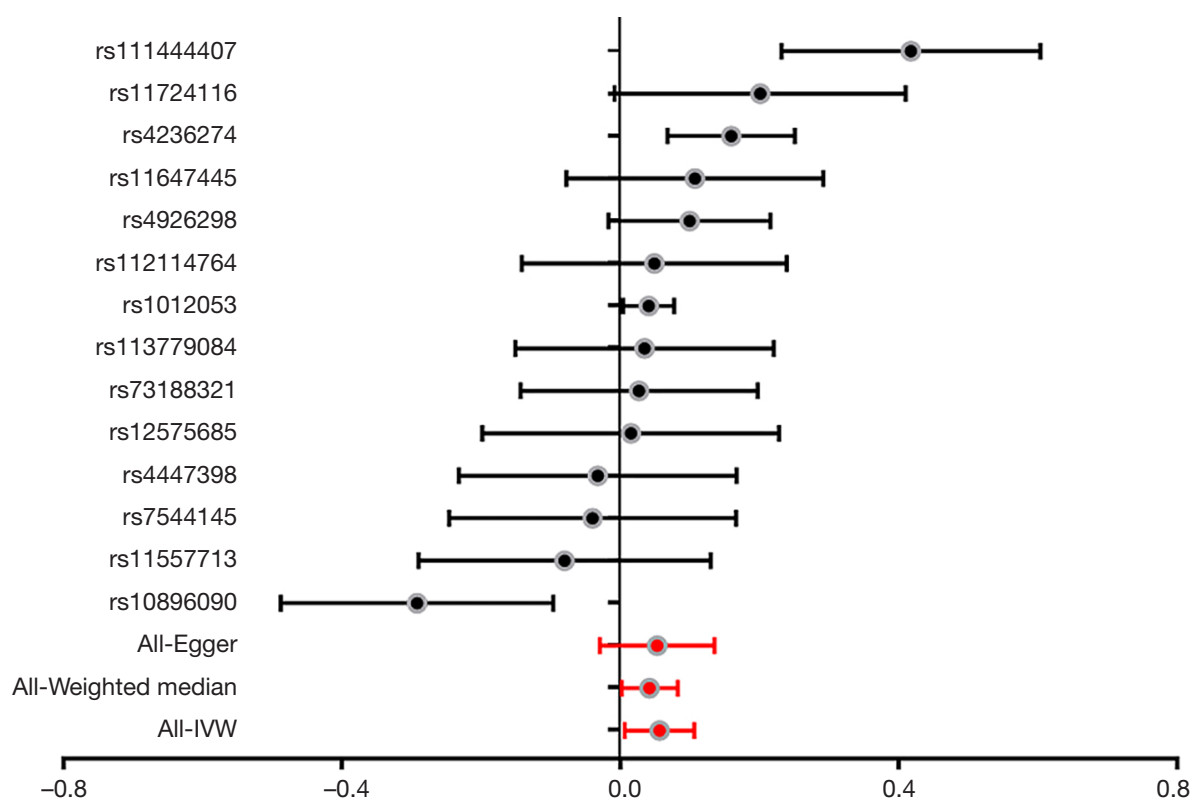

Figure 2 Forest plot of single nucleotide polymorphisms (SNPs) associated with bipolar disorder and their risk of breast cancer. The forest plot shows association of genetic liability to bipolar disorder on breast cancer. Each black point represents the log odds ratio (OR) for breast cancer in bipolar disorder, produced using each of the bipolar disorder SNPs (rs11144407, rs11724116, rs4236274, rs1167445, rs4926298, rs112114764, rs1012053, rs113779084, rs73188321, rs12576775, rs4447398, rs7544145, rs11557713, rs10896090) as separate instruments. Red points show the combined causal estimate using all SNPs together in a single instrument, with three different methods (inverse variance weighted, MR-Egger, and weighted median). Horizontal line segments denote $95 \%$ confidence intervals of the estimate.

Table 6 MR-Egger regression and Heterogeneity analysis of the associations between bipolar disorder and breast cancer overall and immunohistochemical types

\begin{tabular}{|c|c|c|c|c|}
\hline Outcome & \multicolumn{2}{|c|}{ Heterogeneity P } & \multicolumn{2}{|c|}{ MR-Egger regression } \\
\hline Breast cancer overall & 0.0001 & 0.0001 & 0.0006 & 0.9133 \\
\hline ER-positive breast cancer & 0.0060 & 0.0088 & 0.0022 & 0.7140 \\
\hline ER-negative breast cancer & 0.0027 & 0.0031 & -0.0060 & 0.5217 \\
\hline
\end{tabular}

ER, estrogen receptor; IVW, inverse variance weighted.

not correlated with established potential risk factors of breast cancer, including obesity, smoking status, alcohol assumption and use of lithium product.

Previously, the outcomes reported by observational studies on the association between BD and breast cancer were inconsistent, with major demonstrating null or suggestive increases in risk. In 2007, Hippisley-Cox et al. reported that patients with BD and schizophrenia were not correlated with an increased risk of breast cancer from a nested case-control study after adjusting for obesity, smoking, use of NSAIDS and antipsychotics (32). Likewise, a nationwide population-based cohort study conducted in China published by Lin et al. (33), including 20,567 BD patients, elucidated that no association was observed between BD and breast cancer. In 2013, a cohort study from United Kingdom conducted by Osborn et al. examining 106 incident breast cancer events among 20,632 people with SMI (34), denoted a positive association between SMI and breast cancer risk after adjusting for age categories, sex and smoking. Interestingly, the positive association 
Table 7 Causal effects between genetically predicted bipolar disorder and potential confounders and mediators

\begin{tabular}{lcc}
\hline Outcomes & Causal effect $(95 \% \mathrm{Cl})$ & $\mathrm{P}$ value \\
\hline Obesity class 1 (BMl: $\left.30-34.9 \mathrm{~kg} / \mathrm{m}^{2}\right)$ & $0.982(0.900,1.071)$ & 0.6756 \\
Obesity class 2 (BMl: $\left.35-39.9 \mathrm{~kg} / \mathrm{m}^{2}\right)$ & $1.004(0.888,1.136)$ & 0.9446 \\
Obesity class $3\left(\mathrm{BMl}: \geq 40 \mathrm{~kg} / \mathrm{m}^{2}\right)$ & $0.931(0.756,1.146)$ & 0.4979 \\
Previous smoker & $0.998(0.991,1.005)$ & 0.5092 \\
Current smoker & $1.000(0.995,1.005)$ & 0.8926 \\
Alcohol consumption & $0.999(0.987,1.012)$ & 0.9170 \\
Use of lithium product & $1.005(0.977,1.034)$ & 0.7100 \\
\hline
\end{tabular}

BMI, body mass index.

demonstrated by Osborn et al. only limited in obese patients [body mass index $(\mathrm{BMI}) \geq 30 \mathrm{~kg} / \mathrm{m}^{2}$ ] while null association was presented in overall results. More recently, McGinty et al. calculated standardized incidence ratios (SIR) to compare breast cancer incidence among the Maryland Medicaid cohort (3,317 adults with SMI) to the Surveillance Epidemiology and End Results (SEER) population, suggesting breast cancer incidence among participants with schizophrenia or $\mathrm{BD}$ was almost twice higher than the SEER population (SIR 1.9, 95\% CI: 1.1-3.0) (35).

Nevertheless, in view of the characteristics of previous observational studies, reverse causality and potential confounding factors might bias the results. First, the sample size of breast cancer patients in previous studies was relatively limited, with the largest sample size up to 215 , which might lack enough statistical power to precisely evaluate causality between BD and breast cancer risk. Second, several epidemiologic studies $(33,34)$ included people with other mental illnesses such as schizophrenia and depression. Consequently, the results might be biased by a certain type of SMI whereas it remained unclear whether BD was associated with an increased breast cancer risk. Third, only one of the four studies we mentioned above managed to control BMI, and high $\mathrm{BMI}$ is considered an important risk factor for breast cancer, which could also increase risk of $\mathrm{BD}$ (36). Consequently, high BMI could be a confounder for the BD-breast cancer relation and a $\mathrm{BMI}$-independent $\mathrm{BD}$-breast cancer relation could not be assessed effectively. In addition, use of medication for treatment among BD patients, such as lithium product and lamotrigine $(37,38)$, have long been suggested to be correlated with increased cancer risks whereas none of the present studies managed to fully evaluate or verify the correlation between use of antipsychotics and breast cancer risk during the follow-up period. Consequently, biased results could possibly occur. More importantly, to date, no prospective large-scale longitudinal cohort studies have been conducted and thus, it is still insufficient to draw a clear conclusion on the causal relationship from BD to breast cancer.

Plausible mechanisms have been proposed that prolactin (PRL) might play a role for the increased breast cancer risk in BD patients. PRL is a polypeptide hormone secreted by the lactotroph cells of the anterior pituitary gland and its secretion is influenced by both central nervous system (CNS) and peripheral processes (39). The prevalent condition correlated with hyperprolactinemia is stress in response to psychology, use of antidepressants, estrogen and so on (40). Previous studies have reported that BD patients were more vulnerable to hyperprolactinemia $(41,42)$. Meanwhile, epidemiologic studies suggested that use of antipsychotic agents among SMI patients are the most common medications that cause hyperprolactinemia $(38,43)$. Further, both in vivo and epidemiological data supported a crucial role of the hyperprolactinemia that it associates with an increased risk of breast cancer and the occurrence of metastasis (44,45). Mitogenic effects of estrogen (E2) on breast malignancy growth have been well described, that is, the majority of breast cancer cells are responsive to, or dependent on E2 supply (46). Two recent studies showed that PRL can stimulate Ser118 phosphorylation of ER, the modification of which was demonstrated to potentiate transcriptional activity of the unliganded ER or to stabilize ER allowing maintenance of a response to E2 $(47,48)$. In this regard, the elevated concentration of PRL might potentially attribute to the mechanism from BD to breast cancer.

Considering the consistently long incubation period 
between $\mathrm{BD}$ and the occurrence of breast cancer, it is neither suitable nor applicable to investigate the causality through RCTs. From this point of view, our MR approach can give evidence from a new type of study design, which is also in support of a positive relationship between BD and breast cancer. Several strengths of our study are as follow. First, as far as we know, it is the largest study to investigate causality between $\mathrm{BD}$ and risk of breast cancer using genetic variants. Participants were grouped based on their randomly allocated genotype, and this procedure mimicked a RCT. With large sample sizes $(\mathrm{n}=228,951)$ and robustly associated IVs (F-statistics $=27,434.1$ ), our MR study with adequate statistical power could offer a relatively precise estimation of causal effect. It is also the first study to investigate whether effects differed between subgroups stratified by immunohistochemical type. Second, since once BD-associated SNPs included in our study were also correlated with confounding factors, an accurate estimation of the causality between BD and breast cancer would not be provided. Thus, we conducted additional MR analyses which indicated that genetically predicted $\mathrm{BD}$ was not causally associated with the potential confounders, including obesity, smoking and alcohol consumption, suggesting a relatively independent association between $\mathrm{BD}$ and breast cancer. Third, given use of antipsychotics, like lithium product, may increase the incidence of breast cancer among BD patients, we performed additional MR analyses to investigate whether BD-associated SNPs could also be linked to these mediators and the possible potential mechanisms. Our results elucidated that genetically predicted BD was not related to other potential mediators, indicating that the causality between $\mathrm{BD}$ and breast cancer was more likely due to the characteristics of breast cancer itself.

Several limitations should also be considered in our study. First, given bipolar I disorder and bipolar II disorder shared distinct characteristics (49), we were unable to examine the association between different BD phenotypes and risk of breast cancer. Consequently, if our included genetic variants did not represent the risk of all subtypes of $\mathrm{BD}$, our obtained effect estimate was difficult to interpret. Second, though we've used the most comprehensive set of genetic variants so far, it merely explained a part of variance of $\mathrm{BD}$ across individuals. It is possible that some unknown BD-related SNPs could also play an important role in the development of breast cancer. Third, all three MR assumptions cannot be fully examined in our study and potential violations against the assumptions may occur. Due to the fact that the second assumption could not be evaluated directly in our study, additional sensitivity analyses were utilized. The results demonstrated no horizontal pleiotropic effects existed in our study, suggesting the second MR assumption was not violated. Nevertheless, it is possible that some of the genetic variants were also associated with confounders of BD and breast cancer in our study and caution is needed in considering the gross effect. Also, despite that genetic factors are estimated to account for about $10.7 \%$ of the variation, it is worth noting that $\mathrm{BD}$ is mainly determined by social and other environmental factors. Hence, it is inappropriate to deduce that genetic effects are independent of environmental factors.

In conclusion, our present MR study provided relatively strong evidence to suggest that BD plays a causal role in increasing the risk of breast cancer. There is no doubt that cancer prevention is the key to reduce the morbidity and mortality of cancers. Consequently, we should attach great importance to identifying modifiable risk factors correlated with cancers. Afterwards, we can carry out effective interventions to reduce the disease burden worldwide. In 2016, the American Cancer Society had published a review with suggestions at the individual, interpersonal, organizational, community, and policy levels that may improve cancer prevention, screening, and treatment in people with mental illness (50). Nevertheless, in present, both epidemiologic and basic studies concerning the efforts of mental illness on cancer are relatively insufficient. More work is warranted to investigate the potential mechanisms that mediate the association between $\mathrm{BD}$ and breast cancer.

\section{Acknowledgments}

The authors thank Ms. Lindsey Hamblin for helping to edit the manuscript. The authors acknowledge the efforts of the Breast Cancer Association Consortium (BCAC) in providing high quality GWAS data for researchers. The authors acknowledge the efforts of the GWAS consortia in providing high-quality resources in the MR-Base platform (https://www.mrbase.org/) for researchers.

Funding: This work was supported by China National Science Foundation (Grant number 81871893); Key Project of Guangzhou Scientific Research Project (Grant number 201804020030). Cultivation of Guangdong College Students' Scientific and Technological Innovation ("Climbing Program" Special Funds) (Grant number 
pdjh2020a0480).

\section{Footnote}

Peer Review File: Available at http://dx.doi.org/10.21037/ atm-20-5372

Conflicts of Interest: All authors have completed the ICMJE uniform disclosure form (available at http://dx.doi. org/10.21037/atm-20-5372). JH serves as an unpaid editorial board member of Annals of Translational Medicine from Sep 2018 to Aug 2020. The authors have no conflicts of interest to declare.

Etbical Statement: The authors are accountable for all aspects of the work in ensuring that questions related to the accuracy or integrity of any part of the work are appropriately investigated and resolved.

Open Access Statement: This is an Open Access article distributed in accordance with the Creative Commons Attribution-NonCommercial-NoDerivs 4.0 International License (CC BY-NC-ND 4.0), which permits the noncommercial replication and distribution of the article with the strict proviso that no changes or edits are made and the original work is properly cited (including links to both the formal publication through the relevant DOI and the license). See: https://creativecommons.org/licenses/by-nc-nd/4.0/.

\section{References}

1. Harbeck N, Gnant M. Breast cancer. Lancet 2017;389:1134-50.

2. Siegel RL, Miller KD, Jemal A. Cancer statistics, 2020. CA Cancer J Clin 2020;70:7-30.

3. Malvezzi M, Carioli G, Bertuccio P, et al. European cancer mortality predictions for the year 2016 with focus on leukaemias. Ann Oncol 2016;27:725-31.

4. Torre LA, Bray F, Siegel RL, et al. Global cancer statistics, 2012. CA Cancer J Clin 2015;65:87-108.

5. Walker ER, McGee RE, Druss BG. Mortality in mental disorders and global disease burden implications: a systematic review and meta-analysis. JAMA Psychiatry 2015;72:334-41.

6. Colton CW, Manderscheid RW. Congruencies in increased mortality rates, years of potential life lost, and causes of death among public mental health clients in eight states. Prev Chronic Dis 2006;3:A42.
7. Sekula P, Del Greco M F, Pattaro C, et al. Mendelian Randomization as an Approach to Assess Causality Using Observational Data. J Am Soc Nephrol 2016;27:3253-65.

8. Lawlor DA, Harbord RM, Sterne JAC, et al. Mendelian randomization: using genes as instruments for making causal inferences in epidemiology. Stat Med 2008;27:1133-63.

9. Pierce BL, Burgess S. Efficient design for Mendelian randomization studies: subsample and 2-sample instrumental variable estimators. Am J Epidemiol 2013;178:1177-84.

10. Smith GD, Ebrahim S. Mendelian randomization: prospects, potentials, and limitations. Int J Epidemiol 2004:33:30-42.

11. Ikeda M, Takahashi A, Kamatani Y, et al. A genome-wide association study identifies two novel susceptibility loci and trans population polygenicity associated with bipolar disorder. Mol Psychiatry 2018;23:639-47.

12. Burgess S, Scott RA, Timpson NJ, et al. Using published data in Mendelian randomization: a blueprint for efficient identification of causal risk factors. Eur J Epidemiol 2015;30:543-52.

13. Band PR, Le ND, Fang R, et al. Carcinogenic and endocrine disrupting effects of cigarette smoke and risk of breast cancer. Lancet 2002;360:1044-9.

14. Kerr J, Anderson C, Lippman SM. Physical activity, sedentary behaviour, diet, and cancer: an update and emerging new evidence. Lancet Oncol 2017;18:e457-71.

15. Jung S, Wang M, Anderson K, et al. Alcohol consumption and breast cancer risk by estrogen receptor status: in a pooled analysis of 20 studies. Int J Epidemiol 2016;45:916-28.

16. Rouhani M, Ramshini S, Omidi M. The Psychiatric Drug Lithium Increases DNA Damage and Decreases Cell Survival in MCF-7 and MDA-MB-231 Breast Cancer Cell Lines Expos ed to Ionizing Radiation. Curr Mol Pharmacol 2019;12:301-10.

17. Stahl EA, Breen G, Forstner AJ, et al. Genome-wide association study identifies 30 loci associated with bipolar disorder. Nat Genet 2019;51:793-803.

18. Hou L, Bergen SE, Akula N, et al. Genome-wide association study of 40,000 individuals identifies two novel loci associated with bipolar disorder. Hum Mol Genet 2016;25:3383-94.

19. Baum AE, Akula N, Cabanero M, et al. A genome-wide association study implicates diacylglycerol kinase eta (DGKH) and several other genes in the etiology of bipolar disorder. Mol Psychiatry 2008;13:197-207. 
20. Burgess S, Thompson SG. Avoiding bias from weak instruments in Mendelian randomization studies. Int J Epidemiol 2011;40:755-64.

21. Brion M-JA, Shakhbazov K, Visscher PM. Calculating statistical power in Mendelian randomization studies. Int J Epidemiol 2013;42:1497-501.

22. Gamazon ER, Lamba JK, Pounds S, et al. Comprehensive genetic analysis of cytarabine sensitivity in a cell-based model identifies polymorphisms associated with outcome in AML patients. Blood 2013;121:4366-76.

23. Carroll LS, Woolf R, Ibrahim Y, et al. Mutation screening of SCN2A in schizophrenia and identification of a novel loss-of-function mutation. Psychiatr Genet 2016;26:60-5.

24. Burgess S, Butterworth A, Thompson SG. Mendelian randomization analysis with multiple genetic variants using summarized data. Genet Epidemiol 2013;37:658-65.

25. VanderWeele TJ, Tchetgen Tchetgen EJ, Cornelis M, et al. Methodological challenges in mendelian randomization. Epidemiology 2014;25:427-35.

26. Yi JC, Syrjala KL. Anxiety and Depression in Cancer Survivors. Med Clin North Am 2017;101:1099-113.

27. Wang N, Chen C, Zhao L, et al. Vitamin D and Nonalcoholic Fatty Liver Disease: Bi-directional Mendelian Randomization Analysis. EBioMedicine 2018;28:187-93.

28. Zhao Z, Okusaga OO, Quevedo J, et al. The potential association between obesity and bipolar disorder: A metaanalysis. J Affect Disord 2016;202:120-3.

29. Suganthi M, Sangeetha G, Benson CS, et al. In vitro mechanisms involved in the regulation of cell survival by lithium chloride and IGF-1 in human hormonedependent breast cancer cells (MCF-7). Toxicol Lett 2012;214:182-91.

30. Hemani G, Zheng J, Elsworth B, et al. The MR-Base platform supports systematic causal inference across the human phenome. Elife 2018;7:e34408.

31. Burgess S. Sample size and power calculations in Mendelian randomization with a single instrumental variable and a binary outcome. Int J Epidemiol 2014;43:922-9.

32. Hippisley-Cox J, Vinogradova Y, Coupland C, et al. Risk of malignancy in patients with schizophrenia or bipolar disorder: nested case-control study. Arch Gen Psychiatry 2007;64:1368-76.

33. Lin GM, Chen YJ, Kuo DJ, et al. Cancer incidence in patients with schizophrenia or bipolar disorder: a nationwide population-based study in Taiwan, 1997-2009. Schizophr Bull 2013;39:407-16.
34. Osborn DPJ, Limburg H, Walters K, et al. Relative incidence of common cancers in people with severe mental illness. Cohort study in the United Kingdom THIN primary care database. Schizophr Res 2013;143:44-9.

35. McGinty EE, Zhang Y, Guallar E, et al. Cancer incidence in a sample of Maryland residents with serious mental illness. Psychiatr Serv 2012;63:714-7.

36. Burgess JL, Bradley AJ, Anderson KN, et al. The relationship between physical activity, BMI, circadian rhythm, and sleep with cognition in bipolar disorder. Psychol Med 2020:1-9.

37. Kahan NR, Silverman B, Liphshitz I, et al. No apparent association between bipolar disorder and cancer in a large epidemiological study of outpatients in a managed care population. Int Clin Psychopharmacol 2018;33:73-8.

38. Walters J, Jones I. Clinical questions and uncertainty-prolactin measurement in patients with schizophrenia and bipolar disorder. J Psychopharmacol 2008;22:82-9.

39. Adams JB. Human breast cancer: concerted role of diet, prolactin and adrenal C19-delta 5-steroids in tumorigenesis. Int J Cancer 1992;50:854-8.

40. Gold MS, Redmond DE, Donabedian RK, et al. Increase in serum prolactin by exogenous and endogenous opiates: evidence for antidopamine and antipsychotic effects. Am J Psychiatry 1978;135:1415-6.

41. Asnis GM, Nathan RS, Halbreich U, et al. Prolactin changes in major depressive disorders. Am J Psychiatry 1980;137:1117-8.

42. Schmidt M, Sofronescu A, Short B, et al. Increased prolactin concentrations in a patient with bipolar disorder. Clin Chem 2013;59:473-5.

43. Martinsson L, Westman J, Hällgren J, et al. Lithium treatment and cancer incidence in bipolar disorder. Bipolar Disord 2016;18:33-40.

44. Tworoger SS, Hankinson SE. Prolactin and breast cancer etiology: an epidemiologic perspective. J Mammary Gland Biol Neoplasia 2008;13:41-53.

45. Rasmussen LM, Frederiksen KS, Din N, et al. Prolactin and oestrogen synergistically regulate gene expression and proliferation of breast cancer cells. Endocr Relat Cancer 2010;17:809-22.

46. Khalid O, Baniwal SK, Purcell DJ, et al. Modulation of Runx2 activity by estrogen receptor-alpha: implications for osteoporosis and breast cancer. Endocrinology 2008;149:5984-95.

47. Chen Y, Huang K, Chen KE, et al. Prolactin and estradiol utilize distinct mechanisms to increase serine-118 phosphorylation and decrease levels of estrogen receptor 
alpha in T47D breast cancer cells. Breast Cancer Res Treat 2010;120:369-77.

48. González L, Zambrano A, Lazaro-Trueba I, et al. Activation of the unliganded estrogen receptor by prolactin in breast cancer cells. Oncogene 2009;28:1298-308.

Cite this article as: Peng H, Wu X, Ge F, Huo Z, Wen Y, Li C, Lin J, Liang H, Zhong R, Liu J, Wang R, He J, Liang W. Genetically predicted bipolar disorder is causally associated with an increased risk of breast cancer: a two-sample Mendelian randomization analysis. Ann Transl Med 2021;9(5):401. doi: $10.21037 / \mathrm{atm}-20-5372$
49. Carvalho AF, Firth J, Vieta E. Bipolar Disorder. N Engl J Med 2020;383:58-66.

50. Weinstein LC, Stefancic A, Cunningham AT, et al. Cancer screening, prevention, and treatment in people with mental illness. CA Cancer J Clin 2016;66:134-51. 
Supplementary

Table S1 Association between each SNP related to bipolar disorder

\begin{tabular}{|c|c|c|c|c|c|c|c|c|}
\hline SNP & chr & EA & $\beta$ & SE & $\mathrm{P}$-value & EAF & LD exclusion & Study \\
\hline rs7544145 & 1 & $\mathrm{~T}$ & 0.082 & 0.015 & $2.68 \mathrm{E}-08$ & 0.810 & NO & 31043756 \\
\hline rs73188321 & 7 & $\mathrm{~T}$ & -0.083 & 0.013 & $3.65 \mathrm{E}-11$ & 0.330 & NO & \\
\hline rs4447398 & 15 & $A$ & 0.094 & 0.016 & 4.30E-09 & 0.120 & NO & \\
\hline rs3804640 & 3 & A & 0.063 & 0.011 & $9.40 \mathrm{E}-09$ & 0.530 & NO & \\
\hline rs2388334 & 6 & $A$ & -0.062 & 0.011 & $1.24 \mathrm{E}-08$ & 0.520 & NO & \\
\hline rs2302417 & 3 & $A$ & -0.073 & 0.011 & $4.60 \mathrm{E}-11$ & 0.490 & NO & \\
\hline rs12575685 & 11 & A & 0.070 & 0.012 & 3.84E-09 & 0.310 & $\mathrm{NO}$ & \\
\hline rs12226877 & 11 & $A$ & 0.082 & 0.013 & $5.71 \mathrm{E}-10$ & 0.290 & $\mathrm{NO}$ & \\
\hline rs9834970 & 3 & $\mathrm{~T}$ & -0.073 & - & $5.70 \mathrm{E}-12$ & 0.510 & YES & \\
\hline rs7122539 & 11 & $A$ & -0.062 & - & 3.80E-08 & 0.350 & YES & \\
\hline rs61332983 & 2 & I & -0.073 & - & $7.90 \mathrm{E}-10$ & 0.410 & YES & \\
\hline rs59134449 & 10 & 1 & 0.086 & - & $1.20 \mathrm{E}-08$ & 0.160 & YES & \\
\hline rs57970360 & 6 & D & 0.062 & - & $3.50 \mathrm{E}-08$ & 0.440 & YES & \\
\hline rs57195239 & 2 & I & -0.073 & - & 3.80E-09 & 0.340 & YES & \\
\hline rs202012857 & 20 & I & -0.074 & - & $1.10 \mathrm{E}-08$ & 0.280 & YES & \\
\hline rs201231874 & 7 & D & -0.083 & - & $6.20 \mathrm{E}-10$ & 0.250 & YES & \\
\hline rs200550695 & 5 & I & -0.083 & - & $1.50 \mathrm{E}-08$ & 0.820 & YES & \\
\hline rs17183814 & 2 & $A$ & -0.128 & - & 2.00E-09 & 0.075 & YES & \\
\hline rs139221256 & 15 & 1 & -0.073 & - & $2.70 \mathrm{E}-08$ & 0.280 & YES & \\
\hline rs10035291 & 5 & $\mathrm{~T}$ & 0.068 & - & $2.70 \mathrm{E}-08$ & 0.680 & YES & \\
\hline rs11724116 & 4 & $\mathrm{~T}$ & -0.083 & 0.015 & 2.06E-08 & 0.160 & NO & \\
\hline rs11647445 & 16 & $\mathrm{~T}$ & -0.073 & 0.012 & $2.78 \mathrm{E}-10$ & 0.650 & NO & \\
\hline rs11557713 & 18 & $A$ & 0.067 & 0.012 & $2.26 \mathrm{E}-08$ & 0.290 & NO & \\
\hline rs113779084 & 7 & A & 0.073 & 0.012 & $9.62 \mathrm{E}-10$ & 0.300 & $\mathrm{NO}$ & \\
\hline rs112114764 & 17 & $\mathrm{~T}$ & -0.073 & 0.012 & 1.35E-09 & 0.690 & NO & \\
\hline rs111444407 & 19 & $\mathrm{~T}$ & 0.093 & 0.015 & $7.20 \mathrm{E}-10$ & 0.150 & NO & \\
\hline rs10994318 & 10 & C & 0.135 & 0.023 & 3.10E-09 & 0.057 & NO & \\
\hline rs10896090 & 11 & $A$ & 0.081 & 0.014 & 8.48E-09 & 0.810 & NO & \\
\hline rs10744560 & 12 & $\mathrm{~T}$ & 0.073 & 0.012 & $1.92 \mathrm{E}-10$ & 0.340 & $\mathrm{NO}$ & \\
\hline rs10455979 & 6 & C & -0.062 & 0.011 & $2.18 \mathrm{E}-08$ & 0.530 & YES & \\
\hline rs1054442 & 12 & A & 0.122 & 0.018 & $1.00 \mathrm{E}-08$ & 0.620 & YES & 27329760 \\
\hline rs12553324 & 9 & C & 0.113 & 0.021 & $6.00 \mathrm{E}-09$ & 0.590 & NO & \\
\hline rs1487441 & 6 & $G$ & 0.113 & 0.016 & $3.00 \mathrm{E}-08$ & 0.510 & NO & \\
\hline rs2517959 & 17 & $\mathrm{~T}$ & 0.122 & 0.018 & 5.00E-09 & 0.670 & NO & \\
\hline rs4236274 & 7 & $\mathrm{G}$ & 0.140 & 0.022 & 8.00E-12 & 0.390 & NO & \\
\hline rs9834970 & 3 & $\mathrm{~T}$ & 0.131 & 0.020 & $5.00 \mathrm{E}-10$ & 0.500 & YES & \\
\hline rs12576775 & 11 & $\mathrm{G}$ & 0.168 & 0.028 & $3.00 \mathrm{E}-09$ & 0.820 & NO & 28115744 \\
\hline rs174576 & 11 & A & 0.119 & 0.018 & $1.00 \mathrm{E}-10$ & 0.660 & NO & \\
\hline rs28456 & 11 & $\mathrm{G}$ & 0.166 & 0.028 & $6.00 \mathrm{E}-09$ & 0.690 & YES & \\
\hline rs4332037 & 7 & $\mathrm{~T}$ & 0.154 & 0.026 & 2.00E-09 & 0.810 & YES & \\
\hline rs4926298 & 19 & $\mathrm{G}$ & 0.124 & 0.020 & $6.00 \mathrm{E}-10$ & 0.650 & NO & \\
\hline rs9834970 & 3 & C & 0.109 & 0.018 & $2.00 \mathrm{E}-09$ & 0.500 & YES & \\
\hline rs1012053 & 13 & $A$ & 0.464 & 0.083 & $2.00 \mathrm{E}-08$ & 0.840 & NO & 17486107 \\
\hline
\end{tabular}

SNP: single nucleotide polymorphism, se: standard error, LD: linkage disequilibrium, EA: effect allele, EAF: effect allele frequency. 
Table 2 Single SNP result for SNP related to bipolar disorder and risk of breast cancer and subtypes.

\begin{tabular}{|c|c|c|c|c|c|c|c|c|c|}
\hline & exposure & outcome & id.exposure & id.outcome & samplesize & SNP & $\mathrm{b}$ & se & $p$ \\
\hline 1 & $\begin{array}{l}\text { bipolar } \\
\text { disorder }\end{array}$ & $\begin{array}{l}\text { Breast cancer (Combined Oncoarray; iCOGS; } \\
\text { GWAS meta analysis) || id:ieu-a-1126 }\end{array}$ & Fee588 & ieu-a-1126 & 228951 & rs1012053 & $4.16 \mathrm{E}-02$ & $1.83 \mathrm{E}-02$ & 2.32E-02 \\
\hline 2 & $\begin{array}{l}\text { bipolar } \\
\text { disorder }\end{array}$ & $\begin{array}{l}\text { Breast cancer (Combined Oncoarray; iCOGS; } \\
\text { GWAS meta analysis) || id:ieu-a-1126 }\end{array}$ & Fee588 & ieu-a-1126 & 228951 & rs 10896090 & $-2.91 E-01$ & $9.79 \mathrm{E}-02$ & 2.93E-03 \\
\hline 3 & $\begin{array}{l}\text { bipolar } \\
\text { disorder }\end{array}$ & $\begin{array}{l}\text { Breast cancer (Combined Oncoarray; iCOGS; } \\
\text { GWAS meta analysis) || id:ieu-a-1126 }\end{array}$ & Fee588 & ieu-a-1126 & 228951 & rs111444407 & $4.18 \mathrm{E}-01$ & $9.29 \mathrm{E}-02$ & $6.80 \mathrm{E}-06$ \\
\hline 4 & $\begin{array}{l}\text { bipolar } \\
\text { disorder }\end{array}$ & $\begin{array}{l}\text { Breast cancer (Combined Oncoarray; iCOGS; } \\
\text { GWAS meta analysis) || id:ieu-a-1126 }\end{array}$ & Fee588 & ieu-a-1126 & 228951 & rs112114764 & $4.96 \mathrm{E}-02$ & $9.51 \mathrm{E}-02$ & $6.02 \mathrm{E}-01$ \\
\hline 5 & $\begin{array}{l}\text { bipolar } \\
\text { disorder }\end{array}$ & $\begin{array}{l}\text { Breast cancer (Combined Oncoarray; iCOGS; } \\
\text { GWAS meta analysis) || id:ieu-a-1126 }\end{array}$ & Fee588 & ieu-a-1126 & 228951 & rs113779084 & $3.55 \mathrm{E}-02$ & $9.28 \mathrm{E}-02$ & $7.02 \mathrm{E}-01$ \\
\hline 6 & $\begin{array}{l}\text { bipolar } \\
\text { disorder }\end{array}$ & $\begin{array}{l}\text { Breast cancer (Combined Oncoarray; iCOGS; } \\
\text { GWAS meta analysis) || id:ieu-a-1126 }\end{array}$ & Fee588 & ieu-a-1126 & 228951 & rs11557713 & $-7.94 \mathrm{E}-02$ & $1.05 \mathrm{E}-01$ & 4.49E-01 \\
\hline 7 & $\begin{array}{l}\text { bipolar } \\
\text { disorder }\end{array}$ & $\begin{array}{l}\text { Breast cancer (Combined Oncoarray; iCOGS; } \\
\text { GWAS meta analysis) || id:ieu-a-1126 }\end{array}$ & Fee588 & ieu-a-1126 & 228951 & rs11647445 & $1.07 \mathrm{E}-01$ & $9.23 \mathrm{E}-02$ & 2.44E-01 \\
\hline 8 & $\begin{array}{l}\text { bipolar } \\
\text { disorder }\end{array}$ & $\begin{array}{l}\text { Breast cancer (Combined Oncoarray; iCOGS; } \\
\text { GWAS meta analysis) || id:ieu-a-1126 }\end{array}$ & Fee588 & ieu-a-1126 & 228951 & rs11724116 & $2.01 \mathrm{E}-01$ & $1.04 \mathrm{E}-01$ & $5.35 \mathrm{E}-02$ \\
\hline 9 & $\begin{array}{l}\text { bipolar } \\
\text { disorder }\end{array}$ & $\begin{array}{l}\text { Breast cancer (Combined Oncoarray; iCOGS; } \\
\text { GWAS meta analysis) || id:ieu-a-1126 }\end{array}$ & Fee588 & ieu-a-1126 & 228951 & rs 12575685 & $1.56 \mathrm{E}-02$ & $1.06 \mathrm{E}-01$ & 8.83E-01 \\
\hline 10 & $\begin{array}{l}\text { bipolar } \\
\text { disorder }\end{array}$ & $\begin{array}{l}\text { Breast cancer (Combined Oncoarray; iCOGS; } \\
\text { GWAS meta analysis) || id:ieu-a-1126 }\end{array}$ & Fee588 & ieu-a-1126 & 228951 & rs4236274 & 1.60E-01 & 4.57E-02 & 4.65E-04 \\
\hline 11 & $\begin{array}{l}\text { bipolar } \\
\text { disorder }\end{array}$ & $\begin{array}{l}\text { Breast cancer (Combined Oncoarray; iCOGS; } \\
\text { GWAS meta analysis) || id:ieu-a-1126 }\end{array}$ & Fee588 & ieu-a-1126 & 228951 & rs 4447398 & $-3.18 \mathrm{E}-02$ & $9.96 \mathrm{E}-02$ & $7.50 \mathrm{E}-01$ \\
\hline 12 & $\begin{array}{l}\text { bipolar } \\
\text { disorder }\end{array}$ & $\begin{array}{l}\text { Breast cancer (Combined Oncoarray; iCOGS; } \\
\text { GWAS meta analysis) || id:ieu-a-1126 }\end{array}$ & Fee588 & ieu-a-1126 & 228951 & rs4926298 & $1.00 \mathrm{E}-01$ & $5.81 \mathrm{E}-02$ & $8.50 \mathrm{E}-02$ \\
\hline 13 & $\begin{array}{l}\text { bipolar } \\
\text { disorder }\end{array}$ & $\begin{array}{l}\text { Breast cancer (Combined Oncoarray; iCOGS; } \\
\text { GWAS meta analysis) || id:ieu-a-1126 }\end{array}$ & Fee588 & ieu-a-1126 & 228951 & rs73188321 & $2.76 \mathrm{E}-02$ & $8.52 \mathrm{E}-02$ & $7.46 \mathrm{E}-01$ \\
\hline 14 & $\begin{array}{l}\text { bipolar } \\
\text { disorder }\end{array}$ & $\begin{array}{l}\text { Breast cancer (Combined Oncoarray; iCOGS; } \\
\text { GWAS meta analysis) || id:ieu-a-1126 }\end{array}$ & Fee588 & ieu-a-1126 & 228951 & rs7544145 & $-3.92 E-02$ & $1.03 \mathrm{E}-01$ & 7.03E-01 \\
\hline 15 & $\begin{array}{l}\text { bipolar } \\
\text { disorder }\end{array}$ & $\begin{array}{l}\text { Breast cancer (Combined Oncoarray; iCOGS; } \\
\text { GWAS meta analysis) || id:ieu-a-1126 }\end{array}$ & Fee588 & ieu-a-1126 & 228951 & $\begin{array}{l}\text { All - Inverse variance } \\
\text { weighted }\end{array}$ & $5.69 \mathrm{E}-02$ & $2.50 \mathrm{E}-02$ & 2.29E-02 \\
\hline 16 & $\begin{array}{l}\text { bipolar } \\
\text { disorder }\end{array}$ & $\begin{array}{l}\text { Breast cancer (Combined Oncoarray; iCOGS; } \\
\text { GWAS meta analysis) || id:ieu-a-1126 }\end{array}$ & Fee588 & ieu-a-1126 & 228951 & All - MR Egger & $5.33 \mathrm{E}-02$ & $4.11 \mathrm{E}-02$ & 2.19E-01 \\
\hline 17 & $\begin{array}{l}\text { bipolar } \\
\text { disorder }\end{array}$ & $\begin{array}{l}\text { ER+ Breast cancer (Combined Oncoarray; } \\
\text { iCOGS; GWAS meta analysis) || id:ieu-a-1127 }\end{array}$ & Fee588 & ieu-a-1127 & 175475 & rs1012053 & $2.61 \mathrm{E}-02$ & $2.20 \mathrm{E}-02$ & 2.36E-01 \\
\hline 18 & $\begin{array}{l}\text { bipolar } \\
\text { disorder }\end{array}$ & $\begin{array}{l}\text { ER+ Breast cancer (Combined Oncoarray; } \\
\text { iCOGS; GWAS meta analysis) || id:ieu-a-1127 }\end{array}$ & Fee588 & ieu-a-1127 & 175475 & rs10896090 & $-2.34 \mathrm{E}-01$ & $1.17 \mathrm{E}-01$ & 4.44E-02 \\
\hline 19 & $\begin{array}{l}\text { bipolar } \\
\text { disorder }\end{array}$ & $\begin{array}{l}\text { ER+ Breast cancer (Combined Oncoarray; } \\
\text { iCOGS; GWAS meta analysis) || id:ieu-a-1127 }\end{array}$ & Fee588 & ieu-a-1127 & 175475 & rs111444407 & $4.10 \mathrm{E}-01$ & $1.10 \mathrm{E}-01$ & $1.95 \mathrm{E}-04$ \\
\hline 20 & $\begin{array}{l}\text { bipolar } \\
\text { disorder }\end{array}$ & $\begin{array}{l}\text { ER+ Breast cancer (Combined Oncoarray; } \\
\text { iCOGS; GWAS meta analysis) || id:ieu-a-1127 }\end{array}$ & Fee588 & ieu-a-1127 & 175475 & rs112114764 & $2.20 \mathrm{E}-02$ & $1.13 \mathrm{E}-01$ & $8.45 \mathrm{E}-01$ \\
\hline 21 & $\begin{array}{l}\text { bipolar } \\
\text { disorder }\end{array}$ & $\begin{array}{l}\text { ER+ Breast cancer (Combined Oncoarray; } \\
\text { iCOGS; GWAS meta analysis) || id:ieu-a-1127 }\end{array}$ & Fee588 & ieu-a-1127 & 175475 & rs113779084 & $1.16 \mathrm{E}-01$ & $1.11 \mathrm{E}-01$ & 2.94E-01 \\
\hline 22 & $\begin{array}{l}\text { bipolar } \\
\text { disorder }\end{array}$ & $\begin{array}{l}\text { ER+ Breast cancer (Combined Oncoarray; } \\
\text { iCOGS; GWAS meta analysis) || id:ieu-a-1127 }\end{array}$ & Fee588 & ieu-a-1127 & 175475 & rs 11557713 & $-1.80 \mathrm{E}-01$ & $1.24 \mathrm{E}-01$ & 1.48E-01 \\
\hline 23 & $\begin{array}{l}\text { bipolar } \\
\text { disorder }\end{array}$ & $\begin{array}{l}\text { ER+ Breast cancer (Combined Oncoarray; } \\
\text { iCOGS; GWAS meta analysis) || id:ieu-a-1127 }\end{array}$ & Fee588 & ieu-a-1127 & 175475 & rs11647445 & 7.58E-02 & $1.10 \mathrm{E}-01$ & 4.92E-01 \\
\hline 24 & $\begin{array}{l}\text { bipolar } \\
\text { disorder }\end{array}$ & $\begin{array}{l}\text { ER+ Breast cancer (Combined Oncoarray; } \\
\text { iCOGS; GWAS meta analysis) || id:ieu-a-1127 }\end{array}$ & Fee588 & ieu-a-1127 & 175475 & rs11724116 & $1.26 \mathrm{E}-01$ & $1.25 \mathrm{E}-01$ & 3.13E-01 \\
\hline 25 & $\begin{array}{l}\text { bipolar } \\
\text { disorder }\end{array}$ & $\begin{array}{l}\text { ER+ Breast cancer (Combined Oncoarray; } \\
\text { iCOGS; GWAS meta analysis) || id:ieu-a-1127 }\end{array}$ & Fee588 & ieu-a-1127 & 175475 & rs 12575685 & $7.10 \mathrm{E}-03$ & $1.28 \mathrm{E}-01$ & $9.56 \mathrm{E}-01$ \\
\hline 26 & $\begin{array}{l}\text { bipolar } \\
\text { disorder }\end{array}$ & $\begin{array}{l}\text { ER+ Breast cancer (Combined Oncoarray; } \\
\text { iCOGS; GWAS meta analysis) || id:ieu-a-1127 }\end{array}$ & Fee588 & ieu-a-1127 & 175475 & rs 4236274 & $1.17 \mathrm{E}-01$ & $5.50 \mathrm{E}-02$ & $3.32 \mathrm{E}-02$ \\
\hline 27 & $\begin{array}{l}\text { bipolar } \\
\text { disorder }\end{array}$ & $\begin{array}{l}\text { ER+ Breast cancer (Combined Oncoarray; } \\
\text { iCOGS; GWAS meta analysis) || id:ieu-a-1127 }\end{array}$ & Fee588 & ieu-a-1127 & 175475 & rs4447398 & $-9.53 \mathrm{E}-03$ & $1.20 \mathrm{E}-01$ & $9.37 \mathrm{E}-01$ \\
\hline 28 & $\begin{array}{l}\text { bipolar } \\
\text { disorder }\end{array}$ & $\begin{array}{l}\text { ER+ Breast cancer (Combined Oncoarray; } \\
\text { iCOGS; GWAS meta analysis) || id:ieu-a-1127 }\end{array}$ & Fee588 & ieu-a-1127 & 175475 & rs4926298 & $1.81 \mathrm{E}-01$ & $6.94 \mathrm{E}-02$ & $9.20 \mathrm{E}-03$ \\
\hline 29 & $\begin{array}{l}\text { bipolar } \\
\text { disorder }\end{array}$ & $\begin{array}{l}\text { ER+ Breast cancer (C } \\
\text { iCOGS; GWAS meta a }\end{array}$ & Fee588 & ieu-a-1127 & 175475 & rs73188321 & $-2.04 \mathrm{E}-02$ & $1.02 \mathrm{E}-01$ & $8.41 \mathrm{E}-01$ \\
\hline 30 & $\begin{array}{l}\text { bipolar } \\
\text { disorder }\end{array}$ & $\begin{array}{l}\text { ER+ Breast cancer (Combined Oncoarray; } \\
\text { iCOGS; GWAS meta analysis) || id:ieu-a-1127 }\end{array}$ & Fee588 & ieu-a-1127 & 175475 & rs7544145 & $9.44 \mathrm{E}-02$ & $1.24 \mathrm{E}-01$ & 4.46E-01 \\
\hline 31 & $\begin{array}{l}\text { bipolar } \\
\text { disorder }\end{array}$ & $\begin{array}{l}\text { ER+ Breast cancer (Combined Oncoarray; } \\
\text { iCOGS; GWAS meta analysis) || id:ieu-a-1127 }\end{array}$ & Fee588 & ieu-a-1127 & 175475 & $\begin{array}{l}\text { All - Inverse variance } \\
\text { weighted }\end{array}$ & $4.80 \mathrm{E}-02$ & $2.51 \mathrm{E}-02$ & $5.56 \mathrm{E}-02$ \\
\hline 32 & $\begin{array}{l}\text { bipolar } \\
\text { disorder }\end{array}$ & $\begin{array}{l}\text { ER+ Breast cancer (Combined Oncoarray; } \\
\text { iCOGS; GWAS meta analysis) || id:ieu-a-1127 }\end{array}$ & Fee588 & ieu-a-1127 & 175475 & All - MR Egger & 3.61E-02 & $4.11 \mathrm{E}-02$ & 3.97E-01 \\
\hline 33 & $\begin{array}{l}\text { bipolar } \\
\text { disorder }\end{array}$ & $\begin{array}{l}\text { ER- Breast cancer (Combined Oncoarray; } \\
\text { iCOGS; GWAS meta analysis) || id:ieu-a-1128 }\end{array}$ & Fee588 & ieu-a-1128 & 127442 & rs1012053 & $5.22 \mathrm{E}-02$ & $3.36 \mathrm{E}-02$ & 1.21E-01 \\
\hline 34 & $\begin{array}{l}\text { bipolar } \\
\text { disorder }\end{array}$ & $\begin{array}{l}\text { ER- Breast cancer (Combined Oncoarray; } \\
\text { iCOGS; GWAS meta analysis) || id:ieu-a-1128 }\end{array}$ & e588 & ieu-a-1128 & 127442 & rs10896090 & $-4.59 \mathrm{E}-01$ & $1.76 \mathrm{E}-01$ & $9.17 \mathrm{E}-03$ \\
\hline 35 & $\begin{array}{l}\text { bipolar } \\
\text { disorder }\end{array}$ & $\begin{array}{l}\text { ER- Breast cancer (Combined Oncoarray; } \\
\text { iCOGS; GWAS meta analysis) || id:ieu-a-1128 }\end{array}$ & 88 & ieu-a-1128 & 127442 & rs111444407 & $5.10 \mathrm{E}-01$ & $1.67 \mathrm{E}-01$ & $2.33 \mathrm{E}-03$ \\
\hline 36 & $\begin{array}{l}\text { bipolar } \\
\text { disorder }\end{array}$ & $\begin{array}{l}\text { ER- Breast cancer (Combined Oncoarray; } \\
\text { iCOGS; GWAS meta analysis) || id:ieu-a-1128 }\end{array}$ & 88 & ieu-a-1128 & 127442 & rs112114764 & $8.68 \mathrm{E}-02$ & $1.72 \mathrm{E}-01$ & $6.14 \mathrm{E}-01$ \\
\hline 37 & $\begin{array}{l}\text { bipolar } \\
\text { disorder }\end{array}$ & $\begin{array}{l}\text { ER- Breast cancer (Combined Oncoarray; } \\
\text { iCOGS; GWAS meta analysis) || id:ieu-a-1128 }\end{array}$ & Fee588 & ieu-a-1128 & 127442 & rs113779084 & $-8.05 \mathrm{E}-02$ & $1.69 \mathrm{E}-01$ & $6.34 \mathrm{E}-01$ \\
\hline 38 & $\begin{array}{l}\text { bipolar } \\
\text { disorder }\end{array}$ & $\begin{array}{l}\text { ER- Breast cancer (Combined Oncoarray; } \\
\text { iCOGS; GWAS meta analysis) || id:ieu-a-1128 }\end{array}$ & 88 & ieu-a-1128 & 127442 & rs 11557713 & $1.20 \mathrm{E}-02$ & $1.89 \mathrm{E}-01$ & $9.49 \mathrm{E}-01$ \\
\hline 39 & $\begin{array}{l}\text { bipolar } \\
\text { disorder }\end{array}$ & $\begin{array}{l}\text { ER- Breast cancer (Combined Oncoarray; } \\
\text { iCOGS; GWAS meta analysis) || id:ieu-a-1128 }\end{array}$ & 38 & ieu-a-1128 & 1274 & rs11647445 & $2.76 \mathrm{E}-01$ & $1.67 \mathrm{E}-01$ & $9.84 \mathrm{E}-02$ \\
\hline 40 & $\begin{array}{l}\text { bipolar } \\
\text { disorder }\end{array}$ & $\begin{array}{l}\text { ER- Breast cancer (Combined Oncoarray; } \\
\text { iCOGS; GWAS meta analysis) || id:ieu-a-1128 }\end{array}$ & 88 & ieu-a-1128 & 127442 & rs11724116 & $2.18 \mathrm{E}-01$ & $1.93 \mathrm{E}-01$ & $2.58 \mathrm{E}-01$ \\
\hline 41 & $\begin{array}{l}\text { bipolar } \\
\text { disorder }\end{array}$ & $\begin{array}{l}\text { ER- Breast cancer (Combined Oncoarray; } \\
\text { iCOGS; GWAS meta analysis) || id:ieu-a-1128 }\end{array}$ & 88 & ieu-a-1128 & 127442 & rs12575685 & $-1.31 \mathrm{E}-01$ & $1.93 \mathrm{E}-01$ & 4.99E- 01 \\
\hline 42 & $\begin{array}{l}\text { bipolar } \\
\text { disorder }\end{array}$ & $\begin{array}{l}\text { ER- Breast cancer (Combined Oncoarray; } \\
\text { iCOGS; GWAS meta analysis) || id:ieu-a-1128 }\end{array}$ & 88 & ieu-a-1128 & 127442 & rs 4236274 & $6.86 \mathrm{E}-02$ & $8.36 \mathrm{E}-02$ & $4.12 \mathrm{E}-01$ \\
\hline 43 & $\begin{array}{l}\text { bipolar } \\
\text { disorder }\end{array}$ & $\begin{array}{l}\text { ER- Breast cancer (Combined Oncoarray; } \\
\text { iCOGS; GWAS meta analysis) || id:ieu-a-1128 }\end{array}$ & Fee588 & ieu-a- & 1274 & rs4447398 & $-7.42 \mathrm{E}-02$ & $1.81 \mathrm{E}-01$ & $6.82 \mathrm{E}-01$ \\
\hline 44 & $\begin{array}{l}\text { bipolar } \\
\text { disorder }\end{array}$ & $\begin{array}{l}\text { ER- Breast cancer (Combined Oncoarray; } \\
\text { iCOGS; GWAS meta analysis) || id:ieu-a-1128 }\end{array}$ & Fee588 & ieu-a-1128 & 127442 & rs4926298 & $-1.15 \mathrm{E}-01$ & $1.04 \mathrm{E}-01$ & $2.71 \mathrm{E}-01$ \\
\hline 45 & $\begin{array}{l}\text { bipolar } \\
\text { disorder }\end{array}$ & $\begin{array}{l}\text { ER- Breast cancer (Combined Oncoarray; } \\
\text { iCOGS; GWAS meta analysis) || id:ieu-a-1128 }\end{array}$ & 88 & ieu-a-1128 & 127442 & rs73188321 & $2.40 \mathrm{E}-02$ & $1.56 \mathrm{E}-01$ & $8.78 \mathrm{E}-01$ \\
\hline 46 & $\begin{array}{l}\text { bipolar } \\
\text { disorder }\end{array}$ & $\begin{array}{l}\text { ER- Breast cancer (Combined Oncoarray; } \\
\text { iCOGS; GWAS meta analysis) || id:ieu-a-1128 }\end{array}$ & Fee588 & ieu-a-1128 & 127442 & rs7544145 & $-4.98 \mathrm{E}-01$ & $1.86 \mathrm{E}-01$ & $7.56 \mathrm{E}-03$ \\
\hline 47 & $\begin{array}{l}\text { bipolar } \\
\text { disorder }\end{array}$ & $\begin{array}{l}\text { ER- Breast cancer (Combined Oncoarray; } \\
\text { iCOGS; GWAS meta analysis) || id:ieu-a-1128 }\end{array}$ & & ieu-a-1128 & 127442 & $\begin{array}{l}\text { All - Inverse variance } \\
\text { weighted }\end{array}$ & $3.11 \mathrm{E}-02$ & 4.03E-02 & $4.41 \mathrm{E}$ \\
\hline 48 & $\begin{array}{l}\text { bipolar } \\
\text { disorder }\end{array}$ & $\begin{array}{l}\text { ER- Breast cancer (Combined Oncoarray; } \\
\text { iCOGS; GWAS meta analysis) || id:ieu-a-1128 }\end{array}$ & & ieu-a-1128 & 127442 & All - MR Egger & $6.46 \mathrm{E}-02$ & $6.54 \mathrm{E}-02$ & 3.43E-01 \\
\hline
\end{tabular}

SNP: single nucleotide polymorphism, b: beta, se: standard error, p: p-value. 
Table 3 Bi-directional MR analysis on detecting causal effect for breast cancer on bipolar disorder

\begin{tabular}{|c|c|c|c|c|c|c|c|c|c|c|c|c|}
\hline & id.exposure & outcome & exposure & method & b & se & pval & lo_ci & up_ci & or & or_lci95 & or_uci95 \\
\hline 1 & ieu-a-1126 & $\begin{array}{l}\text { Bipolar } \\
\text { disorder }\end{array}$ & $\begin{array}{l}\text { Breast cancer (Combined Oncoarray; iCOGS; } \\
\text { GWAS meta analysis) || id:ieu-a-1126 }\end{array}$ & MR Egger & $-3.89 \mathrm{E}-02$ & $1.11 \mathrm{E}-01$ & 7.27E-01 & $-2.57 \mathrm{E}-01$ & 1.79E-01 & $9.62 \mathrm{E}-01$ & 7.74E-01 & $1.20 \mathrm{E}+00$ \\
\hline 2 & ieu-a-1126 & $\begin{array}{l}\text { Bipolar } \\
\text { disorder }\end{array}$ & $\begin{array}{l}\text { Breast cancer (Combined Oncoarray; iCOGS; } \\
\text { GWAS meta analysis) || id:ieu-a- } 1126\end{array}$ & Weighted median & $-8.52 E-03$ & $6.94 \mathrm{E}-02$ & $9.02 \mathrm{E}-01$ & $-1.44 \mathrm{E}-01$ & $1.27 \mathrm{E}-01$ & $9.92 \mathrm{E}-01$ & $8.65 \mathrm{E}-01$ & $1.14 \mathrm{E}+00$ \\
\hline 3 & ieu-a-1126 & $\begin{array}{l}\text { Bipolar } \\
\text { disorder }\end{array}$ & $\begin{array}{l}\text { Breast cancer (Combined Oncoarray; iCOGS; } \\
\text { GWAS meta analysis) || id:ieu-a- } 1126\end{array}$ & $\begin{array}{l}\text { Inverse variance } \\
\text { weighted }\end{array}$ & 1.19E-03 & 4.71E-02 & $9.80 \mathrm{E}-01$ & $-9.12 \mathrm{E}-02$ & $9.35 \mathrm{E}-02$ & $1.00 \mathrm{E}+00$ & $9.13 \mathrm{E}-01$ & $1.10 \mathrm{E}+00$ \\
\hline 4 & ieu-a-1126 & $\begin{array}{l}\text { Bipolar } \\
\text { disorder }\end{array}$ & $\begin{array}{l}\text { Breast cancer (Combined Oncoarray; iCOGS; } \\
\text { GWAS meta analysis) || id:ieu-a-1126 }\end{array}$ & Simple mode & $3.81 \mathrm{E}-03$ & $1.35 \mathrm{E}-01$ & $9.78 \mathrm{E}-01$ & $-2.61 \mathrm{E}-01$ & $2.68 \mathrm{E}-01$ & $1.00 \mathrm{E}+00$ & 7.70E-01 & $1.31 \mathrm{E}+00$ \\
\hline 5 & ieu-a-1126 & $\begin{array}{l}\text { Bipolar } \\
\text { disorder }\end{array}$ & $\begin{array}{l}\text { Breast cancer (Combined Oncoarray; iCOGS; } \\
\text { GWAS meta analysis) || id:ieu-a- } 1126\end{array}$ & Weighted mode & $3.81 \mathrm{E}-03$ & 8.53E-02 & $9.64 \mathrm{E}-01$ & $-1.63 E-01$ & $1.71 \mathrm{E}-01$ & $1.00 \mathrm{E}+00$ & 8.49E-01 & $1.19 \mathrm{E}+00$ \\
\hline 6 & ieu-a-1127 & $\begin{array}{l}\text { Bipolar } \\
\text { disorder }\end{array}$ & $\begin{array}{l}\text { ER+ Breast cancer (Combined Oncoarray; } \\
\text { iCOGS; GWAS meta analysis) || id:ieu-a- } 1127\end{array}$ & MR Egger & $-5.10 \mathrm{E}-02$ & $1.04 \mathrm{E}-01$ & $6.25 \mathrm{E}-01$ & $-2.55 \mathrm{E}-01$ & $1.53 \mathrm{E}-01$ & $9.50 \mathrm{E}-01$ & 7.75E-01 & $1.16 \mathrm{E}+00$ \\
\hline 7 & ieu-a-1127 & $\begin{array}{l}\text { Bipolar } \\
\text { disorder }\end{array}$ & $\begin{array}{l}\text { ER+ Breast cancer (Combined Oncoarray; } \\
\text { iCOGS; GWAS meta analysis) \|| id:ieu-a-1127 }\end{array}$ & Weighted median & $-1.17 \mathrm{E}-02$ & $6.35 \mathrm{E}-02$ & 8.54E-01 & $-1.36 \mathrm{E}-01$ & $1.13 \mathrm{E}-01$ & $9.88 \mathrm{E}-01$ & 8.73E-01 & $1.12 \mathrm{E}+00$ \\
\hline 8 & ieu-a-1127 & $\begin{array}{l}\text { Bipolar } \\
\text { disorder }\end{array}$ & $\begin{array}{l}\text { ER+ Breast cancer (Combined Oncoarray; } \\
\text { iCOGS; GWAS meta analysis) \|| id:ieu-a- } 1127\end{array}$ & $\begin{array}{l}\text { Inverse variance } \\
\text { weighted }\end{array}$ & 7.97E-03 & 4.39E-02 & 8.56E-01 & $-7.80 \mathrm{E}-02$ & $9.39 \mathrm{E}-02$ & $1.01 \mathrm{E}+00$ & $9.25 \mathrm{E}-01$ & $1.10 \mathrm{E}+00$ \\
\hline 9 & ieu-a-1127 & $\begin{array}{l}\text { Bipolar } \\
\text { disorder }\end{array}$ & $\begin{array}{l}\text { ER+ Breast cancer (Combined Oncoarray; } \\
\text { iCOGS; GWAS meta analysis) } \| \text { id:ieu-a- } 1127\end{array}$ & Simple mode & $-6.33 E-02$ & 1.23E-01 & $6.10 \mathrm{E}-01$ & $-3.05 E-01$ & 1.79E-01 & $9.39 \mathrm{E}-01$ & 7.37E-01 & $1.20 \mathrm{E}+00$ \\
\hline 10 & ieu-a-1127 & $\begin{array}{l}\text { Bipolar } \\
\text { disorder }\end{array}$ & $\begin{array}{l}\text { ER+ Breast cancer (Combined Oncoarray; } \\
\text { iCOGS; GWAS meta analysis) || id:ieu-a- } 1127\end{array}$ & Weighted mode & $-2.54 \mathrm{E}-02$ & 7.67E-02 & 7.41E-01 & $-1.76 \mathrm{E}-01$ & $1.25 \mathrm{E}-01$ & $9.75 \mathrm{E}-01$ & 8.39E-01 & $1.13 \mathrm{E}+00$ \\
\hline 11 & ieu-a-1128 & $\begin{array}{l}\text { Bipolar } \\
\text { disorder }\end{array}$ & $\begin{array}{l}\text { ER- Breast cancer (Combined Oncoarray; } \\
\text { iCOGS; GWAS meta analysis) || id:ieu-a-1128 }\end{array}$ & MR Egger & $1.01 \mathrm{E}-04$ & 1.96E-01 & $1.00 \mathrm{E}+00$ & $-3.84 \mathrm{E}-01$ & 3.84E-01 & $1.00 \mathrm{E}+00$ & $6.81 \mathrm{E}-01$ & $1.47 \mathrm{E}+00$ \\
\hline 12 & ieu-a-1128 & $\begin{array}{l}\text { Bipolar } \\
\text { disorder }\end{array}$ & $\begin{array}{l}\text { ER- Breast cancer (Combined Oncoarray; } \\
\text { iCOGS; GWAS meta analysis) } \| \text { id:ieu-a- } 1128\end{array}$ & Weighted median & $-5.27 \mathrm{E}-02$ & $8.40 \mathrm{E}-02$ & 5.30E-01 & $-2.17 \mathrm{E}-01$ & $1.12 \mathrm{E}-01$ & $9.49 \mathrm{E}-01$ & 8.05E-01 & $1.12 \mathrm{E}+00$ \\
\hline 13 & ieu-a-1128 & $\begin{array}{l}\text { Bipolar } \\
\text { disorder }\end{array}$ & $\begin{array}{l}\text { ER- Breast cancer (Combined Oncoarray; } \\
\text { iCOGS; GWAS meta analysis) || id:ieu-a-1128 }\end{array}$ & $\begin{array}{l}\text { Inverse variance } \\
\text { weighted }\end{array}$ & $-1.00 \mathrm{E}-01$ & $6.08 \mathrm{E}-02$ & $9.90 \mathrm{E}-02$ & $-2.20 \mathrm{E}-01$ & 1.89E-02 & $9.05 \mathrm{E}-01$ & 8.03E-01 & $1.02 \mathrm{E}+00$ \\
\hline 14 & ieu-a-1128 & $\begin{array}{l}\text { Bipolar } \\
\text { disorder }\end{array}$ & $\begin{array}{l}\text { ER- Breast cancer (Combined Oncoarray; } \\
\text { iCOGS; GWAS meta analysis) || id:ieu-a-1128 }\end{array}$ & Simple mode & $-4.09 \mathrm{E}-02$ & $1.45 \mathrm{E}-01$ & 7.81E-01 & $-3.25 \mathrm{E}-01$ & 2.43E-01 & $9.60 \mathrm{E}-01$ & 7.22E-01 & $1.28 \mathrm{E}+00$ \\
\hline 15 & ieu-a-1128 & $\begin{array}{l}\text { Bipolar } \\
\text { disorder }\end{array}$ & $\begin{array}{l}\text { ER- Breast cancer (Combined Oncoarray; } \\
\text { iCOGS; GWAS meta analysis) || id:ieu-a-1128 }\end{array}$ & Weighted mode & $-5.74 \mathrm{E}-02$ & $1.29 \mathrm{E}-01$ & $6.62 \mathrm{E}-01$ & $-3.11 \mathrm{E}-01$ & 1.96E-01 & $9.44 \mathrm{E}-01$ & 7.33E-01 & $1.22 \mathrm{E}+00$ \\
\hline
\end{tabular}

Id: identification, b: beta, se: standard error, or: odds ratio, ci: confidence interval, pval: p-value. 


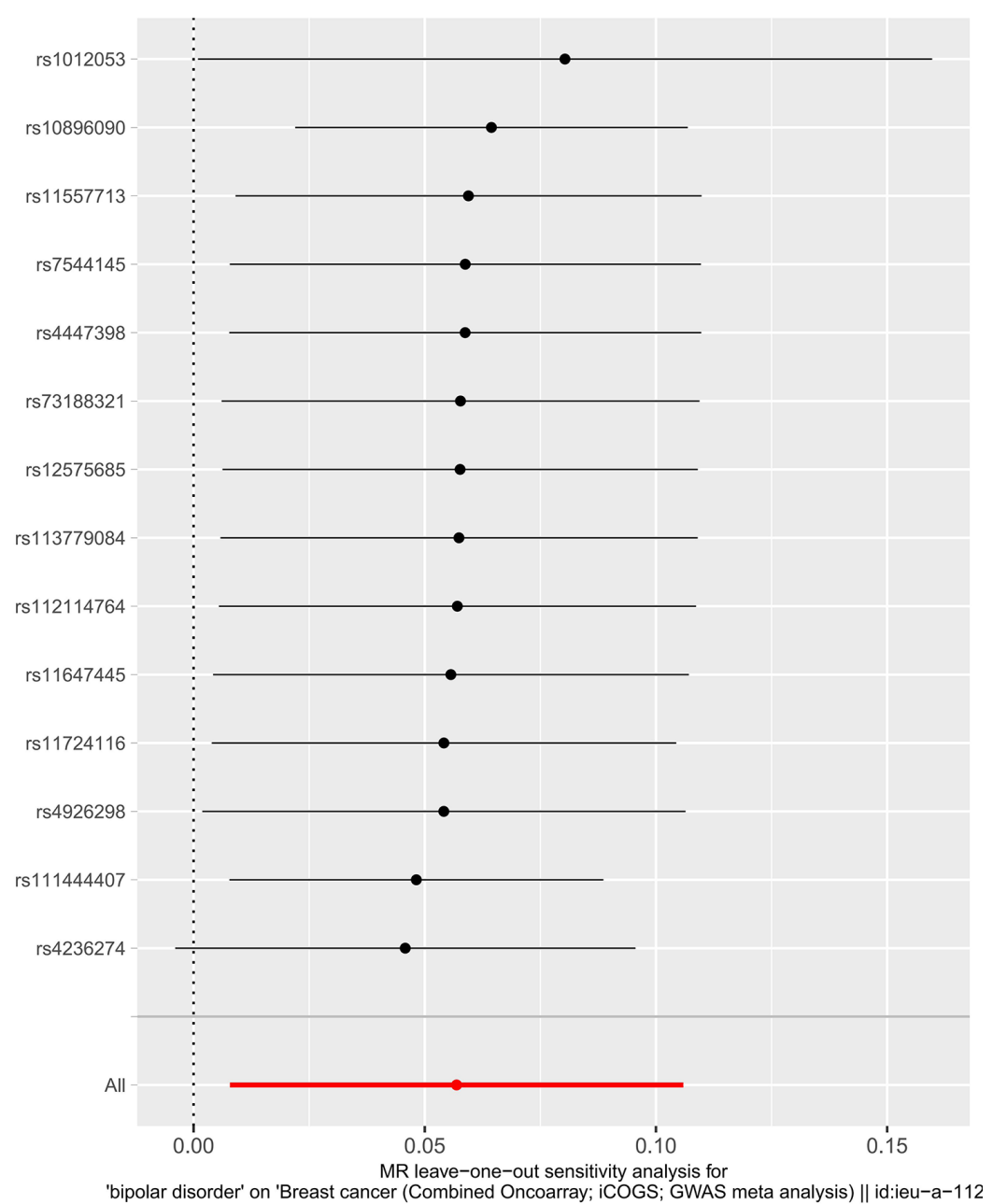

Figure S1 Leave-one-out analysis for genetically predicted bipolar disorder and breast cancer. 


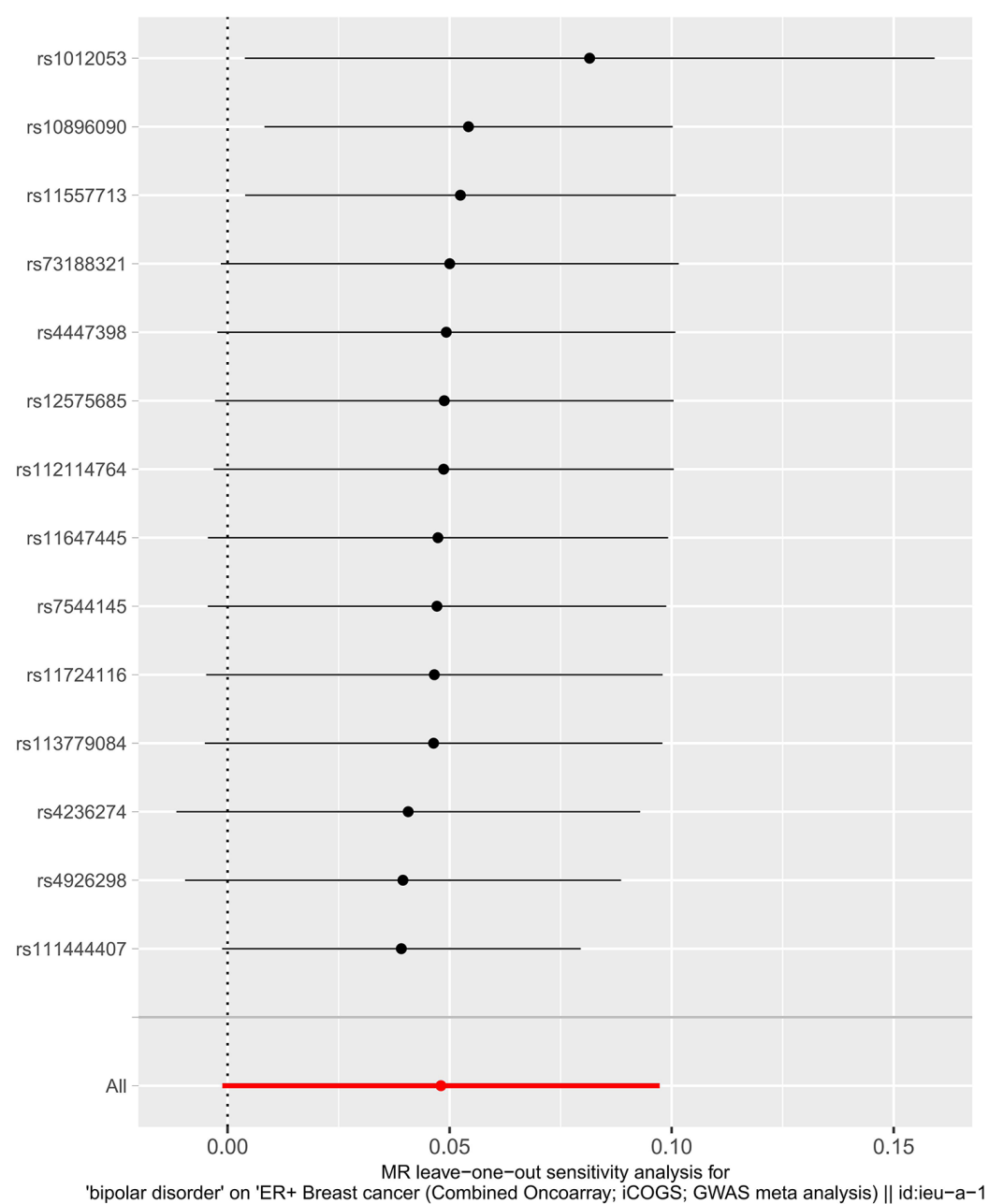

Figure S2 Leave-one-out analysis for genetically predicted bipolar disorder and ER-positive breast cancer. 


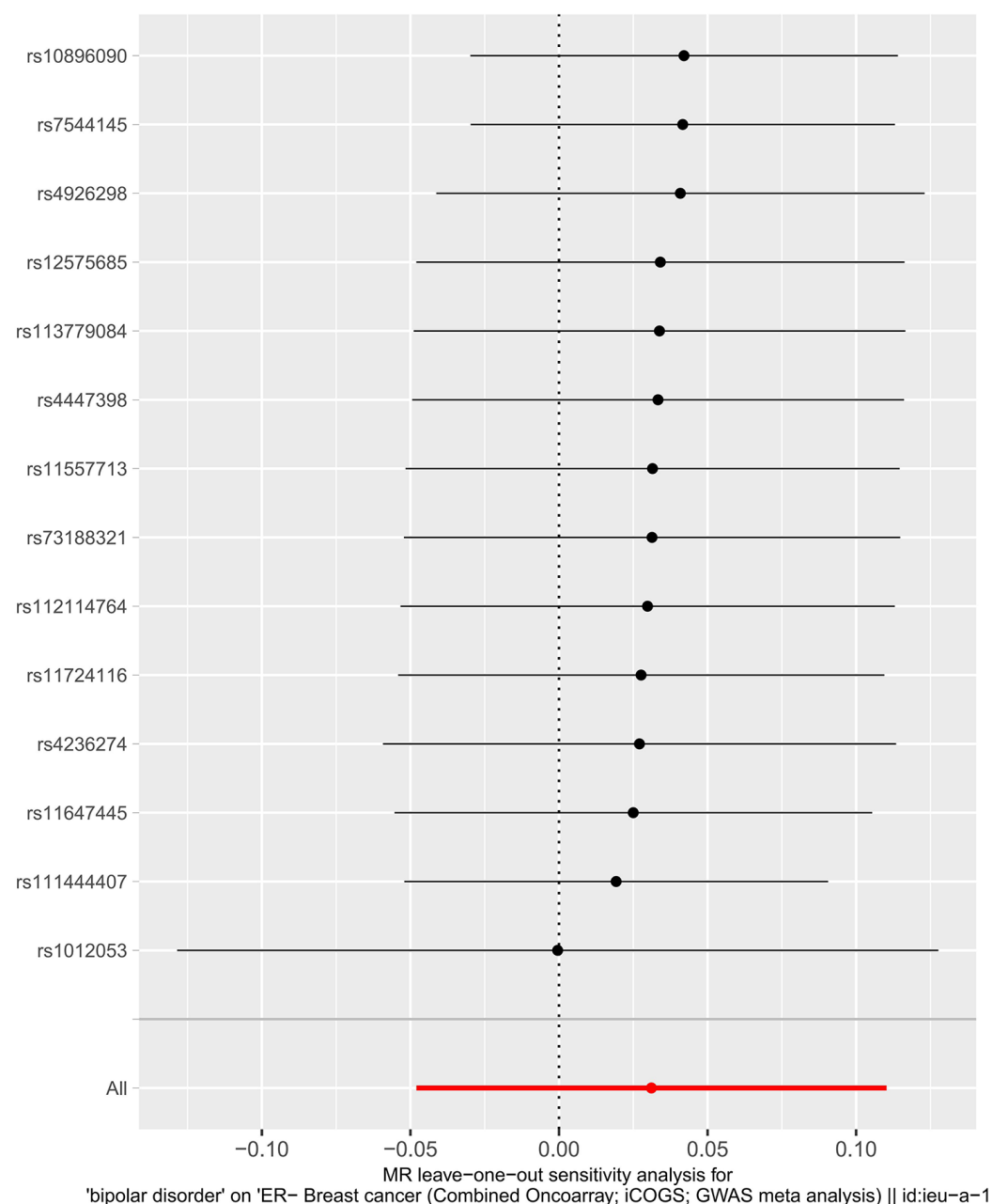

Figure S3 Leave-one-out analysis for genetically predicted bipolar disorder and ER-negative breast cancer. 
Table 4 MR-Egger regression analyses on detecting directional pleiotropy.

\begin{tabular}{|c|c|c|c|c|c|c|c|}
\hline & id.exposure & id.outcome & outcome & exposure & egger intercept & se & pval \\
\hline 1 & Fee588 & ieu-a-1126 & Breast cancer (Combined Oncoarray; iCOGS; GWAS meta analysis) || id:ieu-a-1126 & bipolar disorder & 6.43E-04 & $5.78 \mathrm{E}-03$ & 9.13E-01 \\
\hline 2 & Fee588 & ieu-a-1127 & ER+ Breast cancer (Combined Oncoarray; iCOGS; GWAS meta analysis) || id:ieu-a-1127 & bipolar disorder & $2.16 \mathrm{E}-03$ & $5.76 \mathrm{E}-03$ & 7.14E-01 \\
\hline 3 & Fee588 & ieu-a-1128 & ER- Breast cancer (Combined Oncoarray; iCOGS; GWAS meta analysis) || id:ieu-a-1128 & bipolar disorder & $-6.03 E-03$ & $9.14 \mathrm{E}-03$ & $5.22 \mathrm{E}-01$ \\
\hline
\end{tabular}

se: standard error, pval: $p$-value.

Table S5 MR-heterogeneity test on detecting horizontal pleiotropy.

\begin{tabular}{|c|c|c|c|c|c|c|c|c|}
\hline & id.exposure & id.outcome & outcome & exposure & method & Q & Q_df & Q_pval \\
\hline 1 & Fee588 & ieu-a-1126 & Breast cancer (Combined Oncoarray; iCOGS; GWAS meta analysis) || id:ieu-a-1126 & bipolar disorder & MR Egger & $4.00 \mathrm{E}+01$ & $1.20 \mathrm{E}+01$ & 7.33E-05 \\
\hline 2 & Fee588 & ieu-a-1126 & Breast cancer (Combined Oncoarray; iCOGS; GWAS meta analysis) || id:ieu-a-1126 & bipolar disorder & Inverse variance weighted & $4.00 \mathrm{E}+01$ & $1.30 \mathrm{E}+01$ & 1.39E-04 \\
\hline 3 & Fee588 & ieu-a-1127 & ER+ Breast cancer (Combined Oncoarray; iCOGS; GWAS meta analysis) || id:ieu-a-1127 & bipolar disorder & MR Egger & $2.78 \mathrm{E}+01$ & $1.20 \mathrm{E}+01$ & 5.99E-03 \\
\hline 4 & Fee588 & ieu-a-1127 & ER+ Breast cancer (Combined Oncoarray; iCOGS; GWAS meta analysis) || id:ieu-a-1127 & bipolar disorder & Inverse variance weighted & $2.81 \mathrm{E}+01$ & $1.30 \mathrm{E}+01$ & 8.80E-03 \\
\hline 5 & Fee588 & ieu-a-1128 & ER- Breast cancer (Combined Oncoarray; iCOGS; GWAS meta analysis) || id:ieu-a-1128 & bipolar disorder & MR Egger & $3.01 \mathrm{E}+01$ & $1.20 \mathrm{E}+01$ & 2.69E-03 \\
\hline 6 & Fee588 & ieu-a-1128 & ER- Breast cancer (Combined Oncoarray; iCOGS; GWAS meta analysis) || id:ieu-a-1128 & bipolar disorder & Inverse variance weighted & $3.12 \mathrm{E}+01$ & $1.30 \mathrm{E}+01$ & $3.15 \mathrm{E}-03$ \\
\hline
\end{tabular}

df: degrees of freedom, pval: $p$-value.

Table S6 Association between genetically predicted bipolar disorder and potential confounders and mediators

\begin{tabular}{|c|c|c|c|c|c|c|c|c|c|c|c|c|}
\hline & id.exposure & id.outcome & outcome & exposure & method & nsnp & $\mathrm{b}$ & se & pval & or & or_lci95 & or_uci95 \\
\hline 1 & F8Zizd & ieu-a-1283 & Alcohol consumption || id:ieu-a-1283 & bipolar disorder & MR Egger & 13 & $-7.91 \mathrm{E}-03$ & $9.52 \mathrm{E}-03$ & $4.24 \mathrm{E}-01$ & $9.92 \mathrm{E}-01$ & $9.74 \mathrm{E}-01$ & $1.01 \mathrm{E}+00$ \\
\hline 2 & F8Zizd & ieu-a-1283 & Alcohol consumption || id:ieu-a-1283 & bipolar disorder & Weighted median & 13 & $-2.99 \mathrm{E}-03$ & $6.48 \mathrm{E}-03$ & $6.44 \mathrm{E}-01$ & $9.97 \mathrm{E}-01$ & $9.84 \mathrm{E}-01$ & $1.01 \mathrm{E}+00$ \\
\hline 3 & F8Zizd & ieu-a-1283 & Alcohol consumption || id:ieu-a-1283 & bipolar disorder & $\begin{array}{l}\text { Inverse variance } \\
\text { weighted }\end{array}$ & 13 & $-6.43 \mathrm{E}-04$ & $6.17 \mathrm{E}-03$ & $9.17 \mathrm{E}-01$ & $9.99 \mathrm{E}-01$ & $9.87 \mathrm{E}-01$ & $1.01 \mathrm{E}+00$ \\
\hline 6 & F8Zizd & ieu-a-90 & Obesity class 1 || id:ieu-a-90 & bipolar disorder & MR Egger & 11 & $5.28 \mathrm{E}-02$ & $6.43 \mathrm{E}-02$ & 4.33E-01 & $1.05 \mathrm{E}+00$ & $9.29 \mathrm{E}-01$ & $1.20 \mathrm{E}+00$ \\
\hline 7 & F8Zizd & ieu-a-90 & Obesity class 1 || id:ieu-a-90 & bipolar disorder & Weighted median & 11 & $-1.06 \mathrm{E}-03$ & $3.72 \mathrm{E}-02$ & $9.77 \mathrm{E}-01$ & $9.99 \mathrm{E}-01$ & $9.29 \mathrm{E}-01$ & $1.08 \mathrm{E}+00$ \\
\hline 8 & F8Zizd & ieu-a-90 & Obesity class 1 || id:ieu-a-90 & bipolar disorder & $\begin{array}{l}\text { Inverse variance } \\
\text { weighted }\end{array}$ & 11 & $-1.86 \mathrm{E}-02$ & 4.45E-02 & $6.76 \mathrm{E}-01$ & $9.82 \mathrm{E}-01$ & $9.00 \mathrm{E}-01$ & $1.07 \mathrm{E}+00$ \\
\hline 11 & F8Zizd & ieu-a-91 & Obesity class 2 || id:ieu-a-91 & bipolar disorder & MR Egger & 11 & $1.64 \mathrm{E}-01$ & 7.33E-02 & $5.26 \mathrm{E}-02$ & $1.18 \mathrm{E}+00$ & $1.02 \mathrm{E}+00$ & $1.36 \mathrm{E}+00$ \\
\hline 12 & F8Zizd & ieu-a-91 & Obesity class 2 || id:ieu-a-91 & bipolar disorder & Weighted median & 11 & 7.43E-02 & $6.54 \mathrm{E}-02$ & $2.56 \mathrm{E}-01$ & $1.08 \mathrm{E}+00$ & $9.48 \mathrm{E}-01$ & $1.22 \mathrm{E}+00$ \\
\hline 13 & F8Zizd & ieu-a-91 & Obesity class 2 || id:ieu-a-91 & bipolar disorder & $\begin{array}{l}\text { Inverse variance } \\
\text { weighted }\end{array}$ & 11 & 4.36E-03 & $6.27 \mathrm{E}-02$ & $9.45 \mathrm{E}-01$ & $1.00 \mathrm{E}+00$ & $8.88 \mathrm{E}-01$ & $1.14 \mathrm{E}+00$ \\
\hline 16 & F8Zizd & ieu-a-92 & Obesity class 3 || id:ieu-a-92 & bipolar disorder & MR Egger & 11 & $1.80 \mathrm{E}-02$ & $1.71 \mathrm{E}-01$ & $9.18 \mathrm{E}-01$ & $1.02 \mathrm{E}+00$ & $7.28 \mathrm{E}-01$ & $1.42 \mathrm{E}+00$ \\
\hline 17 & F8Zizd & ieu-a-92 & Obesity class 3 || id:ieu-a-92 & bipolar disorder & Weighted median & 11 & $-1.30 \mathrm{E}-02$ & $1.12 \mathrm{E}-01$ & $9.07 \mathrm{E}-01$ & $9.87 \mathrm{E}-01$ & 7.93E-01 & $1.23 \mathrm{E}+00$ \\
\hline 18 & F8Zizd & ieu-a-92 & Obesity class 3 || id:ieu-a-92 & bipolar disorder & $\begin{array}{l}\text { Inverse variance } \\
\text { weighted }\end{array}$ & 11 & $-7.18 \mathrm{E}-02$ & $1.06 \mathrm{E}-01$ & $4.98 \mathrm{E}-01$ & $9.31 \mathrm{E}-01$ & 7.56E-01 & $1.15 \mathrm{E}+00$ \\
\hline 21 & F8Zizd & ukb-a-224 & Smoking status: Previous || id:ukb-a-224 & bipolar disorder & MR Egger & 14 & $-9.18 \mathrm{E}-03$ & $5.62 \mathrm{E}-03$ & $1.29 \mathrm{E}-01$ & $9.91 \mathrm{E}-01$ & $9.80 \mathrm{E}-01$ & $1.00 \mathrm{E}+00$ \\
\hline 22 & F8Zizd & ukb-a-224 & Smoking status: Previous || id:ukb-a-224 & bipolar disorder & Weighted median & 14 & $-4.62 \mathrm{E}-03$ & $3.33 \mathrm{E}-03$ & $1.66 \mathrm{E}-01$ & $9.95 \mathrm{E}-01$ & $9.89 \mathrm{E}-01$ & $1.00 \mathrm{E}+00$ \\
\hline 23 & F8Zizd & ukb-a-224 & Smoking status: Previous || id:ukb-a-224 & bipolar disorder & $\begin{array}{l}\text { Inverse variance } \\
\text { weighted }\end{array}$ & 14 & $-2.35 E-03$ & $3.56 \mathrm{E}-03$ & $5.09 \mathrm{E}-01$ & $9.98 \mathrm{E}-01$ & $9.91 \mathrm{E}-01$ & $1.01 \mathrm{E}+00$ \\
\hline 26 & F8Zizd & ukb-a-225 & Smoking status: Current || id:ukb-a-225 & bipolar disorder & MR Egger & 14 & $-2.88 \mathrm{E}-03$ & $4.42 \mathrm{E}-03$ & $5.27 \mathrm{E}-01$ & $9.97 \mathrm{E}-01$ & $9.89 \mathrm{E}-01$ & $1.01 \mathrm{E}+00$ \\
\hline 27 & F8Zizd & ukb-a-225 & Smoking status: Current || id:ukb-a-225 & bipolar disorder & Weighted median & 14 & $-1.32 \mathrm{E}-03$ & $2.19 \mathrm{E}-03$ & $5.48 \mathrm{E}-01$ & $9.99 \mathrm{E}-01$ & $9.94 \mathrm{E}-01$ & $1.00 \mathrm{E}+00$ \\
\hline 28 & F8Zizd & ukb-a-225 & Smoking status: Current || id:ukb-a-225 & bipolar disorder & $\begin{array}{l}\text { Inverse variance } \\
\text { weighted }\end{array}$ & 14 & $-3.54 \mathrm{E}-04$ & $2.62 \mathrm{E}-03$ & 8.93E-01 & $1.00 \mathrm{E}+00$ & $9.95 \mathrm{E}-01$ & $1.01 \mathrm{E}+00$ \\
\hline 31 & Xu65Wr & 1126 & $\begin{array}{l}\text { Breast cancer (Combined Oncoarray; } \\
\text { iCOGS; GWAS meta analysis) || id:1126 }\end{array}$ & $\begin{array}{l}\text { Response to lithium } \\
\text { treatment in bipolar } \\
\text { disorder (NA) }\end{array}$ & $\begin{array}{l}\text { Inverse variance } \\
\text { weighted }\end{array}$ & 2 & $5.30 \mathrm{E}-03$ & 1.42E-02 & 7.10E-01 & $1.01 \mathrm{E}+00$ & 9.77E-01 & $1.03 \mathrm{E}+00$ \\
\hline
\end{tabular}

SNP: single nucleotide polymorphism, b: beta, se: standard error, or: odds ratio, $\mathrm{p}$ : $\mathrm{p}$-value, id: identification. 